\title{
Redistribution of tax resources: a cooperative game theory approach
}

\section{Emilio Calvo ${ }^{1}$}

Received: 23 October 2020 / Accepted: 13 October 2021 / Published online: 19 November 2021

(c) The Author(s) 2021

\begin{abstract}
We consider the problem of how to distribute public expenditure among the different regions of an economic entity after all taxes have been collected. Typical examples are: the regions that make up a country, the states of a federal country, or the countries of a confederation of countries. We model the problem as a cooperative game in coalitional form, called the tax game. This game estimates the fiscal resources collected in each region, or coalition of regions, by differentiating between what comes from economic activity within each region and what comes from trade with the other regions. This methodology provides a measure of the disagreement within a region, or coalitions of regions, with respect to the budget received. Similarly, the stability of a budget allocation can be inferred by its situation within the core of the corresponding tax game. We consider the Spanish case as an example and show that the current regional financial system has a moderate degree of instability. We introduce two budget allocation rules, both borrowed from the cooperative games literature: the balanced allocation, which coincides with the nucleolus and with the Shapley value of the tax game, and the weighted balanced allocation, which coincides with the weighted Shapley value. We compare both budget allocation rules with the current Spanish financial system.
\end{abstract}

Keywords Fiscal balances $\cdot$ Budget stability $\cdot$ Coalitional games $\cdot$ Shapley value JEL Classification $\mathrm{H} 77 \cdot \mathrm{C} 71$

\section{Introduction}

This paper addresses the problem of how to distribute public sector spending among the regions of a country. Decisions about how much to spend in each region are increasingly up to local governments. Local institutions want to decide not only on

Emilio Calvo

Emilio.Calvo@uv.es

1 Department of Economic Analysis and ERI-CES, Universitat de Valencia, Valencia, Spain 
what and how to spend the public budget in their region, but also the total amount to be spent in their region.

There are three basic principles ${ }^{1}$ that appear recurrently in the search for a wellfunctioning regional financing system:

1. Non-discrimination Distributed funds must provide a uniform level of public services throughout the country.

2. Fairness in redistribution Allocation of funds should vary directly depending on fiscal needs and inversely according to the tax capacity of each jurisdiction.

3. Ordinality The results of the equalisation should be tolerable for donors and recipients alike. They should narrow financing disparities across regions without altering their per capita relative wealth ranking. They should not carry equalisation beyond a generally acceptable level.

Unfortunately, how to make all these principles fully compatible with each other is not evident. Large disparities between regions in terms of their per capita wealth could make it difficult to apply the principle of non-discrimination, since it could imply high transfers of income from rich to poor regions, always viewed with suspicion by richer regions. When designing a regional financial system, the tax system should therefore minimise the complaints from a region, or group of regions, regarding the total budget obtained following that funding rule. Obviously, how to measure and compare such grievances becomes a key problem in determining the level of equalisation in per capita wealth that should be considered generally acceptable.

This exercise can be transferred, point by point, to the problem of the distribution of the budget between the states of a federal country, or between the states of a confederation of countries, such as the European Union, simply by substituting the regions of a country for the federal states, or by the confederation countries.

Until now, fiscal balances (FBs) were used for the analysis of such complaints. Fiscal balances determine the differences between public revenues collected and public expenditures allocated in each region. These net per capita balances have been used to evaluate and compare the budget distribution between regions.

We can see in the FB literature two opposite (more or less explicit) fiscal sovereignty assumptions, which we might call full versus shared sovereignty. In the full sovereignty approach, all resources collected in a region are considered to belong exclusively to that region. In this case, fiscal balances are used as benchmarks by which the degree of satisfaction or disagreement with the total budgetary expenditure obtained by the region is measured. It should be noted that there is little room for negotiation on budget distribution with this approach. Significant differences between what is collected and obtained are viewed with suspicion. The objective of a stable budget distribution is therefore that what is spent in each region should be as close as possible to what is collected. This is so because the distribution of the budget is seen as a zero-sum game: What one region gains is at the expense of what another loses.

The shared sovereignty approach is opposed to this point of view, in which all the regions that make up a country are considered part of the same economic entity. It is understood that all the resources collected come from the mutual cooperation

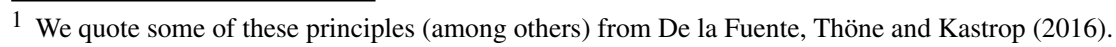


resulting from the exchange of goods and services between the economic agents of the country. From this perspective, regions are distributing all the economic gains from their cooperation between their citizens, regardless of where they are. In the first approach, any monetary transfer is only seen as a voluntary act of solidarity between regions. From the second perspective, it is nothing more than an obligation in order to obtain the common welfare of the country's citizens. However, in our opinion, none of these perspectives are as irreconcilable as they appear at first glance.

In this paper, we address this problem of budget distribution using tools from the theory of cooperative games. We believe this may help clarify the discussion on how much should be allocated to each region. Roughly speaking, the problem can be solved by determining more precisely how much of the fiscal resources belong exclusively to the region (or group of regions), and how much should be considered common property.

We first enrich the FB model by explicitly incorporating interregional economic relationship in its construction. This is accomplished by constructing what we call the tax cooperative game, which determines for each region, or set of regions (coalitions), all tax revenues derived exclusively from the economic interaction within regions of the coalition, as well as any imports or exports from abroad. According to the total sovereignty approach, we can interpret this amount as the minimum that any coalition of regions should receive in any acceptable regional budget allocation. Here, we exclude all tax revenues that coalition members derive from their current interaction with the rest of the country, as according to the shared sovereignty approach they are common property, and consequently, their distribution can be subject to negotiation.

We propose measuring the grievances of a region, or coalition of regions, against the budget distribution, by means of the cooperative game theory concept of the excess of a coalition. This is the difference between what the tax cooperative game gives the coalition minus what the budget allocation spends on it. The lower the allocation given, the greater the excess becomes, and therefore the greater the disagreement. The excess is therefore a measure of such disagreement. The goal is thus to find budget allocations that minimise such excesses.

The familiar concept of the core of a cooperative game is associated with the excesses obtained by the coalitions, i.e. the set of all the budgetary distributions whose excesses are all negative. In this paper, we will continue with the usual custom in game theory of qualifying the stability of a budgetary allocation according to its situation with respect to the core of the tax game. In this way, we will evaluate the stability of the current budgetary distribution of a country, as well as any other alternative proposals we may consider. The first finding was that for any tax cooperative game there are always stable budget allocations. Thus, it is always possible to propose stable budget allocations.

Secondly, we can undertake the theoretical exercise of applying solutions from the cooperative games literature to the tax game at hand. For example, the purpose of the egalitarian spending rule is that no citizen should be discriminated against in terms of public spending, matching the public spending per capita in all regions of a country. Unfortunately, wide disparities in per capita wealth between regions mean that this spending rule easily produces unstable allocations. 
Two other relevant rules are the nucleolus (Schmeidler 1969), which always belongs to the core when it is non-empty, and the Shapley value (Shapley 1953a, b). In general, both rules produce different allocations, and their computation is an arduous task. Nevertheless, given the matrix structure of the tax game, we demonstrate that the nucleolus and the Shapley value of every tax cooperative game coincide. The value formula also takes a simple expression: it assigns each region its own fiscal resources plus half the common fiscal resources of its trade interaction with all other regions. We shall call this rule the balanced allocation $\varphi$, and this is placed at the centre of the core.

However, $\varphi$ does not perform well in terms of wealth redistribution. To improve this poor redistributive behaviour, we propose to consider the weighted balanced allocation $\varphi^{w}$, where the weights $w$ are the per capita gross domestic product $(G D P)$ of regions. Now, the welfare contribution that each region makes to each other in the form of tax transfers is balanced inversely proportional to their GDP per capita. This allocation coincides through its construction with the weighted Shapley value (Shapley 1953a), and we show that it offers a greater degree of solidarity between regions than $\varphi$. Given the convexity of the tax game, this rule is also stable. We thus believe that $\varphi^{w}$ is a reasonable trade-off between these two principles: stability on the one hand, and solidarity on the other one.

Finally, the qualification of a budget distribution as stable or not, depending on whether it is inside or outside the core, is not entirely satisfactory. It is simply a binary assertion. To compare two alternative budget allocations, we would like to know the degree of stability they enjoy. For that purpose, we modify the tax game by means of a parameter $\alpha \in[0,1]$. In the computation of the modified tax game $v_{t}^{\alpha}$ we add a proportion $\alpha$ of the initially excluded tax revenues (considered as a common sovereignty). This parameter allows a gradual transition from the concepts of stability of shared fiscal sovereignty to full fiscal sovereignty. As $\alpha$ increases, therefore, the amount of those common fiscal resources that the region agrees to share with all the others decreases. Accordingly, the set of stable budget allocations reduces to the ideal full sovereignty target $(\alpha=1)$, in which the budgetary expenditure obtained by the region is equal to the totality of taxes collected in it. In addition, $\alpha$ provides a normalised measure of each region's degree of dissatisfaction with respect to a given budget allocation. It is equal to the value $\alpha$ for which the region's excess over the modified tax cooperative game is equal to zero. This normalisation allows a better comparison between the excesses of the regions and, eventually, a comparison between the stability observed in different countries.

We illustrate how the theoretical concepts introduced here perform through a practical exercise: we consider the Spanish case by using fiscal data from 2011 to 2014 . We start by illustrating how to build the tax game from FB and inter-regional commercial trade data. The current Spanish financial rule has a moderate redistributive effect of wealth between regions; the rule treats regions better the poorer they are. Surprisingly, we show that the current financial system belongs (unexpectedly) to the core of the tax game during those years. However, we should nuance the system stability. There are several autonomous communities (CAs) whose excesses are very close to being positive (some, such as Catalonia, with strong secessionist feelings), coexisting with other CAs whose situation in relative terms can be considered privileged, such as 
the group of "foral communities" formed by the Basque Country and Navarre. This situation produces a relatively unstable political cocktail.

Spain involves disparities in terms of per capita wealth across regions, and therefore, as expected, we show that computing the egalitarian rule yields an unstable allocation. The budget distribution of these four rules, the current system, the egalitarian, the balanced allocation $\varphi$, and the weighted balanced allocation $\varphi^{w}$, are compared.

We organise the paper as follows. Following this introduction, Section 2 is dedicated to reviewing the literature related to the problem in both public economics and game theory. Section 3 defines the tax cooperative game and summarises the main stability results. In Sect. 4, we introduce the budget allocation rules $\varphi$ and $\varphi^{w}$. In Sect. 5 we present the extended tax cooperative game associated with $\alpha$. This parameter allows us to consider the degree of stability of any particular budget allocation. Section 6 is dedicated to applying these new concepts to the Spanish case. Section 7 ends with some final comments and remarks. We place the proofs of theorems, and some additional tables, in "Appendix".

\section{Related literature}

The connection between the game theory literature and public finance is not new. Aumann and Kurz (1977) made an early application of the Shapley value to political taxation, where the individual taxes are the Shapley value of an income distribution game, built as follows: each agent starts with an individual endowment. Redistribution decisions are made by majority voting, but each agent has the right to destroy part of their endowment. In some sense, we take a parallel approach to that work: in their case, players are citizens, and in our case, players are regions. In both, the Shapley value is applied. Another influential paper is O'Neill (1982). He has contributed to a body of work on fair division in the face of conflicting claims. Note that a taxation problem is formally identical to a claim problem. A claim rule specifies how to divide a fixed amount $E$ between a set of agents whose claims are $d_{1}, d_{2}, \ldots$, and $\sum d_{i}>E$. A taxation rule specifies how to divide the tax burden $X$ (the amount of taxes to be collected) among the agents whose gross incomes are $y_{1}, y_{2}, \ldots$, and $\sum y_{i}>X$. Starting with the work of Young $(1988,1990)$ on equal sacrifice and distributive justice in taxation, there has been a trend of research applying tools from the claim problems literature to analysing tax rules and defining new ones. A good example is MorenoTernero and Villar (2006). For an extensive survey of this topic, see Thomson (2003, 2019). Differently to our problem, players in this literature are citizens and not regions; and secondly, and more importantly, our problem is purely re-distributive. However, as we have transformed the problem of distributing the public budget among regions in a cooperative tax game setting, many of the properties used to evaluate cooperative solutions could also be used to evaluate every tax spending rule, and that is a promising field of future research.

Fiscal balances analysis has increased over time. For example, the FBs for Spain have been estimated by Castells et al. (2000), Uriel and Barberán (2007), LópezCasanovas and Rosselló-Villalonga (2014), and De la Fuente et al. (2014). For Italy, they have been estimated by Ferraro and Zanardi (2011), and in Giannola et al. (2016); 
for the UK by McLean and McMillan (2003), Oxford Economics (2008) and Office for National Statistics (2018a, b); for Ireland by Morgenroth (2010); for the USA by Dubay (2006) and the Tax Foundation (2007); and for Canada by Ruggeri (2010). De la Fuente (2014) compares Catalonia with similar regions in other countries. Monastell and Sánchez (2012) analyse the territorial redistribution of the public budget in Spain and make comparative studies of the FB involving several countries.

Our contribution in this paper is to enrich the FB model by disaggregating the taxes collected in each region according to the origin of their commercial relationship with each other. We build a cooperative tax game from this, where the worth of a coalition of regions is the sum of the tax revenues derived exclusively from the economic interaction within them. As far as we know, this approach is novel within the FB literature. The cooperative tax game obtained has a special matrix structure, and in particular, it is the sum of an additive game plus a two-person game. This provides the convexity of the game and the simplicity of the computation of the balanced (and the weighted balanced) tax allocation. These two-person games were considered (and in general, k-person games) in van den Noweland et al. (1996), showing the coincidence of the Shapley value and the nucleolus. These games were applied to a telecommunication problem. Recent application of games with this matrix structure includes Bergantiños and Moreno-Ternero (2020) to broadcasting sports events and López-Navarerrete et al. (2019) to smart TV ecosystems.

Convexity plays a crucial role in guaranteeing the existence of stable tax rules. Convex games have non-empty cores (Shapley 1971; Ichiishi 1981), and so tax games do too. The concept of $\varepsilon$-core was introduced for the analysis of games with empty cores (Shapley and Shubik 1996; Maschler et al. 1979), mainly to enlarge the set of quasi-stable allocations, recovering non-emptiness. The least core is at the centre of the $\varepsilon$-core. The $\varepsilon$-core converges towards the least core as $\varepsilon$ grows. Motivated by the political consideration that the tax revenue vector $T$ is the target aspiration of an independent fiscal authority, we have replaced the least core by $T$ as the convergence point of the $\alpha$-cores, $C\left(N, v_{t}^{\alpha}\right)$. This modification of the least core concept is very specific to our tax game setting, and it has no clear counterpart in a general cooperative game.

The balanced tax allocation introduced in Sect. 4 is just the Shapley value of the tax game $\left(N, v_{t}^{0}\right)$. Apart from Shapley's original characterisation of his value (Shapley 1953a, b), several other characterisations have been outlined in the literature, for example, by Myerson (1980), Young (1988), Hart and Mas-Colell (1989), Feltkamp (1995), and van den Brink (2001), among others. We note that the property of equally sharing the profits of cooperation between every two regions, which we have used in the definition of the balanced tax rule, is just a forward translation of the property of balanced contributions introduced by Myerson (1980), for TU games. Myerson used efficiency and balanced contributions to give one of the simplest axiomatic characterisations of this value. The weighted balanced allocation is just the weighted Shapley value of the tax game. This weighted version of the value was introduced by Shapley (1953a). Its axiomatic characterisation by means of weighted balanced contributions was given in Hart and Mas-Colell (1989). For the role of weights in the value, see Kalai and Samet (1987), Monderer et al. (1992), and Calvo et al. (2000). Further 
interpretation of the balanced contributions axiom can be found in Calvo and Santos (2000).

\section{Tax cooperative model}

Denote by $N=\{1,2, \ldots, n\}$ the set of regions in a country. The FBs determine the balance between the regional distribution of public expenditure and revenue flow. Broadly speaking, public sector expenditure is the total capital and current expenditure (mainly wages and salaries, goods and services, and expenditure on fixed capital, but also subsidies, social benefits, and other transfers) of central government and local government bodies, as well as public sector-controlled corporations. Public sector revenue is the total current receipts (mainly taxes, but also social contributions, interest, dividends, gross operating surplus, and transfers) received by central government and local government bodies, as well as public sector-controlled corporations. Net fiscal balance is the gap between total spending and revenue raised. A negative net fiscal balance represents a surplus, meaning that a region is receiving more in revenue than it is spending. A positive net fiscal balance represents a deficit, meaning a region is spending more than it is receiving in revenue. ${ }^{2}$

Our goal is to quantify how much of the fiscal resources collected in one region come from commercial interaction with the other regions in a country. We can build the cooperative tax game by means of this interregional disaggregation of the FBs. Thus, we use the commercial exchange matrix ${ }^{3} \boldsymbol{C}$ of goods and services between regions of a country, and between them and abroad, and use it to obtain matrices $I$ and $\boldsymbol{R}$ of indirect and direct tax revenues, respectively. We will obtain the tax cooperative game from them.

In order to clarify the exposition, we will use a simple numerical example to illustrate the theoretical concepts as they are introduced.

The trade exchange matrix $\boldsymbol{C}=\left[\begin{array}{cc}c & x \\ m\end{array}\right]$ gathers the flow of goods and services between the regions of a country, and between them and abroad:

$$
C=\begin{array}{ccccc|c|}
\hline c_{11} & \cdots & c_{1 i} & \cdots & c_{1 n} & x_{1} \\
\vdots & & \vdots & & \vdots & \vdots \\
c_{i 1} & \cdots & c_{i i} & \cdots & c_{i n} & x_{i} \\
\vdots & & \vdots & & \vdots & \vdots \\
c_{n 1} & \cdots & c_{n i} & \cdots & c_{n n} & x_{n} \\
\hline m_{1} & \cdots & m_{i} & \cdots & m_{n} & \\
\hline
\end{array}
$$

\footnotetext{
${ }^{2}$ Definitions taken from Office for National Statistics (2018a). A detailed explanation of the concepts used in the construction of the FBs can be found in Office for National Statistics (2018b), and De la Fuente et al. (2014).

${ }^{3}$ In the following, matrices will be in bold.
} 
That is, for each region $i, c_{i j}$ is the amount of goods and services from region $i$ sold to region $j, m_{i}$ are imports from abroad to $i$, and $x_{i}$ are exports from $i$ to abroad. Rows thus indicate sales and columns purchases.

For example, let $N=\{1,2,3\}$ be a country with three regions, and with the corresponding trade exchange matrix.

$C=$\begin{tabular}{|ccc|c|}
\hline 3.5 & 2 & 3 & 1 \\
3 & 8 & 4 & 2 \\
2 & 6 & 6.75 & 2 \\
\cline { 1 - 2 } 2 & 2 & 2 & \multicolumn{1}{|c}{} \\
\cline { 1 - 2 } & &
\end{tabular}

The population of the three regions is given by the vector $P=(10,7,7)$, and the wealth of each region is given by the vector of gross domestic product $G D P=(16,24.5,22)$. The gross domestic product per capita of each region $i$; that is, $G D P_{i} / P_{i}$, is given by the vector $(1.6,3.5,3.14)$, and so we will consider regions 2 and 3 richer than region 1 in relative terms.

Let us call $T_{i}$ the total public revenue of the region $i$. The vector of regional public revenues is denoted by $T=\left(T_{1}, \ldots, T_{n}\right)$. We also denote the sum of all tax revenues by $T(N)=\sum_{i \in N} T_{i}$.

In order to make a proper territorial allocation of the origin of these revenues, we must first separate indirect taxes from the rest of the income. This is because consumption bears indirect taxes: VAT and excise duties on alcoholic beverages, energy products and electricity, manufactured tobacco, etc. In fact, in the construction of the FBs, the total indirect tax collected in each region is calculated by distributing the total revenues of a country among the regions according to their consumption (purchases). According to this approach, we will follow the same procedure to assign the origin of the indirect tax collected in each region according to the origin of its consumption. Let $I_{i}$ be the total indirect taxes collected on $i$. The sum of all the coefficients in column $i$ of matrix $\boldsymbol{C}$ yields the total consumption of region $i$. We therefore distribute these taxes in proportion of the column coefficients of $\boldsymbol{C}$.

Then, the coefficients of column $i$ of indirect taxes are:

$$
I_{j i}=\frac{c_{j i}}{\sum_{j \in N} c_{j i}+m_{i}} \cdot I_{i}, \forall j \in N ; \text { and } I_{i}^{m}=\frac{m_{i}}{\sum_{j \in N} c_{j i}+m_{i}} \cdot I_{i}
$$

The $I_{j i}$ coefficient corresponds to the indirect taxes collected on $i$ as a result of the purchase of goods and services $c_{j i}$ from region $j$, and the $I_{i}^{m}$ coefficient with the custom tariffs associated with the imports $m_{i}$. Thus, we obtain matrix $\boldsymbol{I}$, where each column gives the distribution of indirect taxes collected in each region by origin. 


$$
I=\begin{array}{ccccc}
I_{11} & \cdots & I_{1 i} & \cdots & I_{1 n} \\
\vdots & & \vdots & & \vdots \\
I_{i 1} & \cdots & I_{i i} & \cdots & I_{i n} \\
\vdots & & \vdots & & \vdots \\
I_{n 1} & \cdots & I_{n i} & \cdots & I_{n n} \\
\hline I_{1}^{m} & \cdots & I_{i}^{m} & \cdots & I_{n}^{m} \\
\hline
\end{array}
$$

As a result, the average tax rate $\tau_{i}^{I}$ of indirect taxes levied on region $i$ is given by

$$
\tau_{i}^{I}=\frac{I_{i}}{\sum_{j \in N} c_{j i}+m_{i}}, \forall i \in N
$$

In general, these rates will differ between regions, ${ }^{4}$ as they do not necessarily coincide in the same consumption patterns. ${ }^{5}$ Note that $I_{j i}=c_{j i} \cdot \tau_{i}^{I}, \forall j \in N$; and $I_{i}^{m}=$ $m_{i} \cdot \tau_{i}^{I}$.

In our example, suppose that $I=(2.1,3.6,6.3)$ is the vector of indirect tax revenues. The corresponding indirect tax matrix is

$$
I=\begin{array}{lll|}
0.7 & 0.4 & 1.2 \\
0.6 & 1.6 & 1.6 \\
0.4 & 1.2 & 2.7 \\
\hline 0.4 & 0.4 & 0.8 \\
\hline
\end{array}
$$

Then, the corresponding average tax rates of indirect tax revenues are:

$$
\tau_{1}^{I}=\frac{2.1}{10.5}=0.2, \tau_{2}^{I}=\frac{3.6}{18}=0.2, \tau_{3}^{I}=\frac{6.3}{15.75}=0.4
$$

We can interpret these differences to mean that, for ecological considerations, region 3 taxes on fuel and other industrial chemicals are higher than in regions 1 and 2 .

Let $R_{i}$ be the rest of the region's tax revenues: direct taxes, social security, local government taxes, etc. These taxes are determined by the production of goods and services sold within the region, the sales to other regions, and the exports abroad. The sum of all the coefficients in the row $i$ of matrix $\boldsymbol{C}$ yields the total sales of region $i$. The breakdown of these taxes by rows gives the following coefficients:

$$
R_{i j}=\frac{c_{i j}}{\sum_{j \in N} c_{i j}+x_{i}} \cdot R_{i}, \forall j \in N ; \text { and } R_{i}^{x}=\frac{x_{i}}{\sum_{j \in N} c_{i j}+x_{i}} \cdot R_{i} .
$$

\footnotetext{
4 And also, between different blocs (coalitions) of regions.

5 VAT, excise duties, electricity, hydrocarbon, among others, are all different from each other. Therefore, different proportions in their consumption will give rise to different average rates. Even between different regions, the tax rate applied to the same product may vary.
} 
The $R_{i j}$ coefficient corresponds to the tax revenues collected on $i$ as a result of the sales of goods and services $c_{i j}$ to region $j$ and the $R_{i}^{x}$ coefficient with the tax revenues associated with the exports $x_{i}$. In this way we obtain matrix $\boldsymbol{R}$, where (by rows) we have broken down the direct tax revenues of each region by destination.

$$
R=\begin{array}{ccccc|c|}
\hline R_{11} & \cdots & R_{1 i} & \cdots & R_{1 n} & R_{1}^{x} \\
\vdots & & \vdots & & \vdots & \vdots \\
R_{i 1} & \cdots & R_{i i} & \cdots & R_{i n} & R_{i}^{x} \\
\vdots & & \vdots & & \vdots & \vdots \\
R_{n 1} & \cdots & R_{n i} & \cdots & R_{n n} & R_{n}^{x} \\
\hline
\end{array}
$$

Correspondingly, the average tax rate $\tau_{i}^{R}$ of direct tax revenues levied on region $i$ is given by

$$
\tau_{i}^{R}=\frac{R_{i}}{\sum_{j \in N} c_{i j}+x_{i}}, \forall i \in N
$$

Again, these regional rates may differ, as regions do not necessarily coincide in the same production patterns. Note that $R_{i j}=c_{i j} \cdot \tau_{i}^{R}, \forall j \in N$; and $R_{i}^{x}=x_{i} \cdot \tau_{i}^{R}$.

In our example, let $R=(1.9,3.4,6.7)$ be the vector of direct tax revenues.

Its corresponding direct tax matrix is

$$
R=\begin{array}{lll|l|}
\hline 0.7 & 0.4 & 0.6 & 0.2 \\
0.6 & 1.6 & 0.8 & 0.4 \\
0.8 & 2.4 & 2.7 & 0.8 \\
\hline
\end{array}
$$

The average tax rates of direct revenues are:

$$
\tau_{1}^{R}=\frac{1.9}{9.5}=0.2, \tau_{2}^{R}=\frac{3.4}{17}=0.2, \tau_{3}^{R}=\frac{6.7}{16.75}=0.4
$$

We can interpret these differences, assuming that the fiscal system of region 3 is more progressive than regions 1 and 2 .

In this way, the total tax income of region $i$ will be the sum of the coefficients of column $i$ of matrix $\boldsymbol{I}$, plus, those of row $i$ of matrix $\boldsymbol{R}$. That is,

$$
T_{i}=I_{i}+R_{i}=\left(\sum_{j \in N} I_{j i}+I_{i}^{m}\right)+\left(\sum_{j \in N} R_{i j}+R_{i}^{x}\right)
$$

Given a set of regions $N$, and tax matrices $\boldsymbol{R} \in \mathbb{R}_{+}^{n \times n+1}$ and $\boldsymbol{I} \in \mathbb{R}_{+}^{n+1 \times n}$, the triple $(N, \boldsymbol{R}, \boldsymbol{I})$ is called a tax problem. The space of tax problems with region set $N$ is denoted by $\mathcal{T}^{\mathrm{N}}$ and by $\mathcal{T}$ the space of all tax problems. 
Remark We wish to stress that the average tax rates $\tau_{i}^{I}$ and $\tau_{i}^{R}$ are not necessary to obtain the taxes collected in each region. It is the other way around: the data from which to calculate the tax matrices $\boldsymbol{I}$ and $\boldsymbol{R}$, by linear approximation for practical purposes, are the matrix $\boldsymbol{C}$ an tax vectors $I$ and $R$. Once the computation of $\boldsymbol{I}$ and $\boldsymbol{R}$ is done, we can calculate the average rates by region or by coalition of regions if desired. The whole analysis of the cooperative tax game can be done without any reference to these average tax rates. Indeed, when a coalition of regions is considered, the fiscal aggregation obtained is only for accounting purposes, and we assume that it has no political consequences, such as the equalisation of the tax rates applied for all the regions of the coalition. Throughout the analysis it is assumed that these tax rates are fixed, regardless of which coalition $S$ we are considering. In short, we are not interested in finding out what the economic consequences will be if a coalition of regions forms an independent economic and fiscal entity. We just want to account how much tax we can attribute to coalition $S$ and coalition $N \backslash S$; and how much tax is the consequence of cooperation between $S$ and $N \backslash S$.

A budget allocation rule $\psi$ is a vector function, $\psi: \mathcal{T}^{\mathrm{N}} \rightarrow \mathbb{R}^{\mathrm{N}}$, which for each problem $(N, \boldsymbol{R}, \boldsymbol{I})$ specifies how to redistribute all taxes collected among the regions. Given a budget allocation $\psi$, the Fiscal Balances are the differences between the total public revenue collected within each region and the public spending allocated to it:

$$
F B_{i}(\psi)=T_{i}-\psi_{i}, \quad \forall i \in N
$$

A positive value implies a transfer of income to other regions. A negative balance means being a net receptor. The lower this value, the better the relative situation of the region from the point of view of regional income redistribution.

Generally, the state budget is not necessarily in balance; it may be in deficit, $\sum_{i \in N} F B_{i}(\psi)<0$, or budget surplus, $\sum_{i \in N} F B_{i}(\psi)>0$. The size of the budget deficit/surplus changes over time as a function of the economic cycle. We therefore need a balanced budget if we want to compare two different budget allocations ( $\psi$ and $\psi^{\prime}$ ') for the same year in a consistent way, or analyse the evolution of $\psi$ in successive years. We can therefore either adjust expenditure or revenue. Debt financing increases the level of spending from which the population can benefit. Thus, we distribute the payment of the deficit among the population that benefits from it. Consequently, we follow the rule of allocating debt payments among the regions in proportion to their population, and adjust revenues to match expenditures. We call neutralising the FBs the operation of balancing the budget. That is, let $D=\sum_{i \in N} \psi_{i}-\sum_{i \in N} T_{i}$ be the total debt, and let $P=\left(P_{i}\right)_{i \in N}$ be the vector of regional population. We distribute the debt of each region by

$$
D_{i}=\frac{P_{i}}{\sum_{j \in N} P_{j}} \cdot D, \forall i \in N
$$

The adjusted total revenues of region $i$ are $A T_{i}=T_{i}+D_{i}$, and its adjusted fiscal balance is given by

$$
A F B_{i}(\psi)=A T_{i}-\psi_{i}, \quad \forall i \in N
$$


We will use gross domestic product $(G D P)$ as a reference of the level of wealth of a region. To measure the redistributive influence that the current spending rule $\psi$ has on $G D P$, or if we want to compare the impact that an alternative rule $\chi$ have, we need to calculate what the initial GDP of each region would be without the transfers originated by the current rule $\psi$. This is what we call IGDP. And, because the present $G D P$ was originated by $\psi$, we denote it by $\psi G D P$. Then, we have that

$$
I G D P_{i}=\psi G D P_{i}+A F B_{i}(\psi), \quad \forall i \in N
$$

We denote the final GDP associated with any other budget allocation rule $\phi$ by $\phi G D P$, and it is equal to the $I G D P$ minus the fiscal balance associated with it, that is, the payoffs given by the rule $\phi$ to the region minus the total tax revenues of the region, hence:

$$
\phi G D P_{i}=I G D P_{i}-A F B_{i}(\phi), \quad \forall i \in N
$$

Let us suppose, in our example, that the distribution of the budget strictly follows the principle of non-discrimination. That is, the total budget is shared between regions in proportion to its population, in such a way that the expenses per capita are the same in every region. We call this the egalitarian spending rule, $E g$. Let $P \in \mathbb{R}_{++}^{N}$ be a vector of population, where $P_{i}$ is the population of region $i \in N$. Therefore, $E g$ is given by

$$
E g_{i}=\frac{P_{i}}{\sum_{j \in N} P_{j}} \cdot T(N), \quad \forall i \in N
$$

In our example, Region 1 is the poorest region in relation to regions 2 and 3 . The total taxes collected are

$$
T=I+R=(2.1,3.6,6.3)+(1.9,3.4,6.7)=(4,7,13) ; \quad T(N)=24
$$

The payoffs of the population egalitarian rule are:

$E g_{1}=\frac{10}{24} \cdot 24=10, \quad E g_{2}=E g_{3}=\frac{7}{24} \cdot 24=7$.

The fiscal balances associated with this rule, $F_{i}(E g)=T_{i}-E g_{i}$, are

$$
F B_{1}(E g)=4-10=-6, \quad F B_{2}(E g)=7-7=0, \quad F B_{3}(E g)=13-7=6
$$

Note that we are assuming a zero deficit, i.e. $\sum_{i \in N} F B_{i}(E g)=-6+0+6=0$. Here, region 3 is making a transfer of 6 units of wealth to region 1.

Because we are assuming that the current spending rule is the egalitarian rule, the vector $G D P=(16,24.5,22)$ is then the final gross domestic product associated with $E g$, i.e. $G D P \equiv E g G D P$. The vector of total public revenues is $T=(4,7,13)$. The vector of FBs associated with the egalitarian rule is $F B(E g)=T-E g=(-6,0,6)$. This means that the vector of initial gross domestic product is $I G D P=G D P+$ $F B(e g)=(16,24.5,22)+(-6,0,6)=(10,24.5,28)$. 
Now we are ready to build the tax cooperative game, but first we remind some basic definitions brought from the literature of cooperative games. A transferable utility game (TU-game for short) is given by a pair $(N, v)$ where $N$ is a finite set of players, with cardinality $\# N=n$, and $v: 2^{N} \rightarrow \mathbb{R}$ is a characteristic function, which assigns to every coalition $S \subset N$ a real number $v(S)$, satisfying $v(\emptyset)=0$. The set $2^{N}$ denotes the set of all subsets of $N$, called coalitions, and for each $S \subset N, v(S)$ is called the worth of $S$. This amount is interpreted as the payoff that is available to the coalition, and there are no restrictions on how this payoff may be divided among the members of the coalition. The space of games with finite player set $N$ is denoted by $\mathcal{G}^{N}$ and by $\mathcal{G}$ the space of all games. Given a game $(N, v)$ and coalition $S$, we write $(S, v)$ for the subgame obtained by restricting $v$ to subsets of $S$ only (i.e. to $2^{S}$ ).

Given a tax problem $(N, \boldsymbol{R}, \boldsymbol{I})$ and a vector of regional debts $\left(D_{1}, \ldots, D_{n}\right)$, we denote by $\left(N, v_{t}\right) \in \mathcal{G}^{N}$ its associated tax cooperative game, defined by

$$
v_{t}(S)=\sum_{i \in S}\left[\sum_{j \in S}\left(R_{i j}+I_{j i}\right)+R_{i}^{x}+I_{i}^{m}+D_{i}\right], \quad \forall S \subset N
$$

The worth $v_{t}(S)$ is the sum of the tax revenues derived exclusively from the economic interaction within regions of $S$ and abroad, plus its public debt.

In the definition of $v_{t}$ we exclude from public resources collected by the region, those that come from commercial interaction with other regions of the country. We should not consider these resources when measuring the difference between what the state spends in the region, and what the region could spend on its own because the resources that we have excluded are the property of both the region and the rest of the regions that make up the state.

Continuing with our numerical example, the worth of the game associated with coalition $\{1,2\}$ is calculated as:

$$
\begin{aligned}
v_{t}(\{1,2\})= & {\left[\left(R_{11}+I_{11}\right)+\left(R_{12}+I_{21}\right)+R_{1}^{x}+I_{1}^{m}\right] } \\
& +\left[\left(R_{21}+I_{12}\right)+\left(R_{22}+I_{22}\right)+R_{2}^{x}+I_{2}^{m}\right] \\
= & {[(0.7+0.7)+(0.4+0.6)+0.2+0.4] } \\
& +[(0.6+0.4)+(1.6+1.6)+0.4+0.4]=8
\end{aligned}
$$

Making the same for all coalitions, it is easy to check that:

$$
\begin{aligned}
v_{t}(\{1\}) & =2, v_{t}(\{2\})=4, v_{t}(\{3\})=7, v_{t}(\{1,2\})=8, v_{t}(\{1,3\}) \\
& =12, v_{t}(\{2,3\})=17, v_{t}(\{1,2,3\})=24
\end{aligned}
$$

Now, let $\psi$ be the current regional distribution of current public expenditure. To measure the disagreement that a region, or group of regions, has with respect to $\psi$, we will use the concept of excess. The excess of $S$ in $\psi$, denoted by $e(S)$, is defined by 


$$
e(S)=v_{t}(S)-\sum_{i \in S} \psi_{i}
$$

The less $S$ obtains with $\psi$, the greater its excess, and therefore the greater its degree of dissatisfaction with $\psi$. Looking for the minimisation of the excesses, we wonder if it is possible to find tax allocations whose excesses are all negative. Note that the concept of excess is consistent with that of fiscal balances. It could be interpreted as the "fiscal balance" of coalition $S$ with respect to tax game $v_{t}$.

The set of all allocations with non-positive excesses is the familiar notion of the core of a cooperative game (Gillies 1953). We denote it by $C\left(N, v_{t}\right)$. That is,

$$
C\left(N, v_{t}\right)=\left\{x \in \mathbb{R}^{n}: \sum_{i \in N} x_{i}=v_{t}(N) \wedge e(S) \leq 0, \forall S \subset N\right\}
$$

The core is the set of allocations that exhaust the budgetary constraint, $\sum_{i \in N} x_{i}=$ $v_{t}(N)$, and where no coalition has a positive excess, $e(S) \leq 0$.

We consider a budget allocation rule unstable if it produces allocations that do not belong to the core of the tax game. That is, outside the core it is highly likely that the allocation provides a high degree of dissatisfaction $(e(S)>0)$ with the budget allocated to some regions. ${ }^{6}$

Therefore, we must first study the existence of stable budget allocations, because if the tax game associated with a country has an empty core, this will imply that any redistribution of the budget spending will always be unsatisfactory for some regions. A predictable consequence will be the existence of permanent disagreements, impossible to solve by redistributive budget spending policies alone. One way to solve such issues could be by increasing budget expenditures in all regions simultaneously, but at the expense of falling into wasteful fiscal debt, with harmful financial consequences in the end.

The main result ${ }^{7}$ of this section is of a positive nature: every tax game has stable budget allocations.

Theorem 1 For every tax problem $(N, \boldsymbol{R}, \boldsymbol{I}) \in \mathcal{T}^{N}$, the core of its associated tax game $\left(N, v_{t}\right)$ is always non-empty: $C\left(N, v_{t}\right) \neq \varnothing$. In particular, $T \in C\left(N, v_{t}\right)$.

This result opens the door for political cooperation because, from an economic perspective, it is always possible to agree on some stable regional budget distribution.

In our example, to see the inequalities that satisfy every stable allocation $x$, note that, for region 1 it must hold that $x_{1} \geq v_{t}(1)=2$, and for regions 2 and 3 that $x_{2}+x_{3} \geq v_{t}(\{2,3\})=17$, which jointly with $\sum_{i \in N} x_{i}=v_{t}(\{1,2,3\})=24$, implies that $x_{1} \leq v_{t}(N)-x_{2}-x_{3}=24-17=7$. Following the same reasoning for regions 2 and 3 , we realise that the core of the game $\left(N, v_{t}\right)$ is the set.

$$
C\left(N, v_{t}\right)=\left\{\left(x_{1}, x_{2}, x_{3}\right) \in \mathbb{R}^{3}: 2 \leq x_{1} \leq 6 ; 4 \leq x_{2} \leq 12 ; 7 \leq x_{3} \leq 16\right\}
$$

\footnotetext{
6 In Sect. 4, we will discuss the degree of stability of an allocation in more detail.

7 We give all proofs in "Appendix".
} 


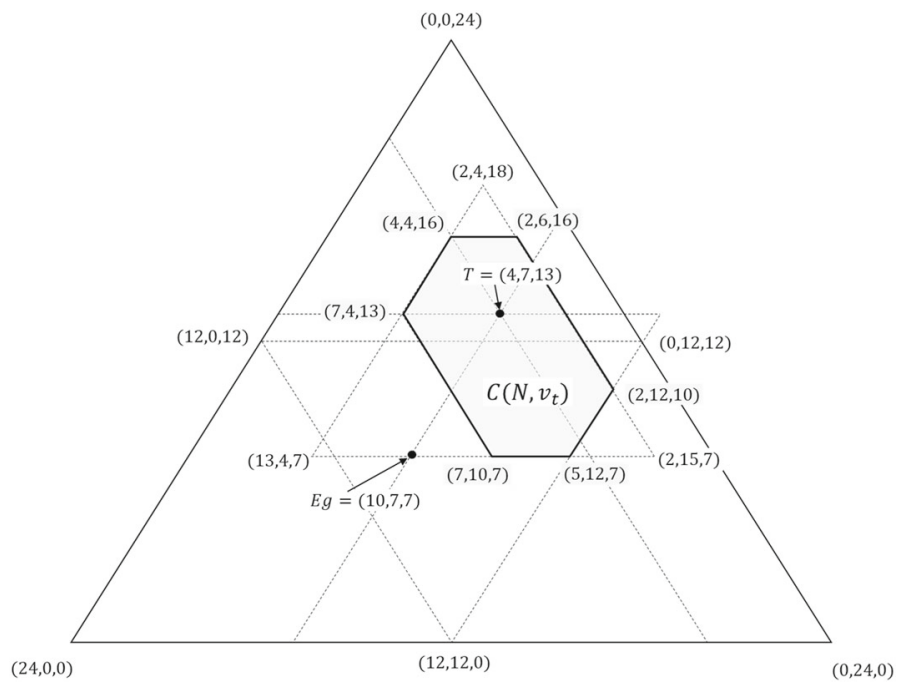

Fig. 1 Core representation

which turns out to be the convex hull of the following vertices:

$$
C\left(N, v_{t}\right)=C_{H}\{(7,4,13),(4,4,16),(2,6,16),(2,12,10),(5,12,7)\} .
$$

We can represent all these points graphically with the help of the equilateral triangle given in Fig. 1 Core representation.

This triangle represents all efficient and non-negative payoffs. For example, for region 3, the bottom side represents allocations where region 3 obtains zero. The vertex $(0,0,24)$ is the opposite case, where region 3 obtains the total taxes to share. Each intermediate horizontal line represents a constant payoff for region 3 (between 0 and 24). The same happens for regions 1 and 2, with parallel lines of constant payoffs, between the maximum payoff of 24 in the vertex and the minimum 0 payoff on its opposite side.

The core $C\left(N, v_{t}\right)$ of this game is the shadow area of the hexagon in Fig. 1 Core representation, and we can see the vector of public revenues $T=(4,7,13)$ is inside the core.

In our example, region 1 is the poorest region in relation to regions 2 and 3 . The payoffs of the egalitarian rule are $E g=(10,7,7)$. This allocation is not in the core, because coalition $\{2,3\}$ has a positive excess,

$$
e(\{2,3\})=v_{t}(\{2,3\})-\left(E g_{2}+E g_{3}\right)=17-(7+7)=3>0 .
$$

In our example, the transfers of wealth imposed by egalitarian rule are incompatible with its stability, as it can see that $E g \notin C\left(N, v_{t}\right)$. 


\section{Balanced allocations rules}

So far, we have identified those allocations that are in the core of the tax game as stable, and those that are outside of it as unstable. In the definition of the cooperative tax game $v_{t}$ we have made the assumption that when we calculate the fiscal tax resources to which a coalition $S$ has access, those that are the consequence of the commercial exchange with the other regions $N \backslash S$ cannot be included as their own, since those resources should be considered as common property of $S$ and $N \backslash S$.

Under the stability approach followed here, we could ask which budget allocation is the most stable of all. As the goal is to minimise the excesses of coalitions (minimising their dissatisfaction), we have two possible answers, both drawn from cooperative game theory literature: the nucleolus and the Shapley value.

The nucleolus was introduced in Schmeidler (1969). The idea behind this value is to select an allocation that minimises the dissatisfaction of the most dissatisfied coalition, where the dissatisfaction of an allocation $x$ by coalition $S \subseteq N$ is measured by its excess $e(S)$. For that purpose, it makes the largest dissatisfaction as small as possible. If there are several allocations to do this, then we make the second largest dissatisfaction as small as possible, and so on until we reach a unique allocation. The nucleolus is thus the unique allocation that minimises lexicographically the excesses of coalitions. In this sense, the nucleolus is similar in spirit to the maximin principle of distributive justice proposed by Rawls (1971). Moreover, the nucleolus is always in the core when the core is non-empty. There are several procedures to compute the nucleolus, but it can be quite hard. ${ }^{8}$

The Shapley value was introduced by Shapley (1953a, b). When a game is convex (as all tax games are $^{9}$ ) the Shapley value turns out to be its core barycentre. Thus, it also becomes a good stable allocation proposal. To calculate it in a tax game, we need to obtain all the vertices that delimit the core, making its arithmetic mean (all being equally likely). Note that, in general, the Shapley value and the nucleolus select different points, even for convex games. This leads us to expect that the nucleolus and the Shapley value of a tax game could be different. Surprisingly, it turns out that both values coincide in any tax game. Moreover, its calculus is straightforward and has an intuitive interpretation in terms of fairness. For reasons that will be evident in the following, we will call it the balanced allocation $\varphi$.

Following the common sovereignty assumption, the fiscal resources resulting from the economic exchange between regions $i$ and $j$ are the tax benefits of economic cooperation between both regions. Those amounts are $\left(R_{i j}+I_{j i}\right)$ for region $i$ and $\left(R_{j i}+I_{i j}\right)$ for region $j . R_{i j}$ and $I_{i j}$ come from $c_{i j}$ sales of goods and services from $i$ to $j$, and $R_{j i}$ and $I_{j i}$ come from $c_{j i}$ sales from $j$ to $i$. How do we could distribute these benefits between both regions? A standard solution in two-person games is to equally share the benefits of cooperation. In accordance with this principle, we will assign each region its own fiscal resources, $R_{i i}+I_{i i}+R_{i}^{x}+I_{i}^{m}$, plus half of the common fiscal resources of its commercial interaction with each of the other regions.

\footnotetext{
8 See Maschler (1992) for a review of those procedures. The MATLAB toolbox package MatTuGames provided by Meinhardt (2012) is useful for practical computations.

9 See Theorem 6 in "Appendix".
} 
To simplify the notation, we denote

$$
t_{i i}=R_{i i}+I_{i i}+R_{i}^{x}+I_{i}^{m} \text {, and } t_{i j}=R_{i j}+I_{j i}, \quad \forall j \neq i .
$$

Then, for any tax problem $(N, \boldsymbol{R}, \boldsymbol{I}) \in \mathcal{T}^{\mathrm{N}}$, the balanced allocation $\varphi$ is defined by

$$
\varphi_{i}(N, \boldsymbol{R}, \boldsymbol{I})=t_{i i}+\frac{1}{2} \sum_{j \in N \backslash i}\left(t_{i j}+t_{j i}\right), \forall i \in N
$$

We may say that with the tax rule $\varphi$ the budget contribution of region $i$ to $j$ and the budget contribution of $j$ to $i$ are the same, that is $\frac{1}{2}\left(t_{i j}+t_{j i}\right)$. In the following theorem, the coincidence of the balanced allocation and the Shapley value of the tax game is established.

Theorem 2 For every tax problem $(N, \boldsymbol{R}, \boldsymbol{I}) \in \mathcal{T}^{N}$, the balanced allocation $\varphi$ coincides with the Shapley value and the nucleolus of the tax game $\left(N, v_{t}\right) .{ }^{10}$

Thus, $\varphi$ is a budget allocation located at the centre of the core.

Going back to our numerical example, we show the calculation of $\varphi$ for region 1 .

$$
\begin{aligned}
\varphi_{1}= & t_{11}+\frac{1}{2}\left(t_{12}+t_{21}\right)+\frac{1}{2}\left(t_{13}+t_{31}\right) \\
= & (0.7+0.7+0.2+0.4)+\frac{1}{2}[(0.4+0.6)+(0.6+0.4)] \\
& +\frac{1}{2}[(0.6+0.4)+(0.8+1.2)]=4.5
\end{aligned}
$$

Making the same calculation for regions 2 and 3, it is easy to check that the vector of balance allocations is equal to $\varphi=(4.5,8,11.5)$. We have made a close-up of the core in Fig. 2 Close-up of the core below and it can be seen that $\varphi$ is located in the centre of it.

It should be noted that regional redistribution of wealth was not an initial purpose in the design of the balanced allocations rule $\varphi$. Therefore, we cannot expect good redistributive behaviour accordingly when applied in countries with an uneven distribution of wealth. This is the case in our numerical example. We have assumed that the current spending rule is the egalitarian rule, $E g=(10,7,7)$. Hence, the final gross domestic product associated with $E g$ is $E g G D P=(16,24.5,22)$. Given the population vector $P=(10,7,7)$, the per capita ${ }^{11} E g G D P$ is $E g G D P^{h}=(1.6,3.5,3.14)$. The vector of total public revenues is $T=(4,7,13)$, and the vector of FBs associated with the egalitarian rule is $F B(E g)=T-E g=(-6,0,6)$. The vector of initial gross domestic product is therefore $I G D P=G D P+F B(e g)=(16,24.5,22)+(-6,0,6)=$ $(10,24.5,28)$, and the per capita $I G D P$ is $I G D P^{h}=(1,3.5,4)$. There is a wide

\footnotetext{
10 The $\tau$-value (Tijs 1981) also coincide with the Shapley value and the nucleolus in the class of two-player games. It is easy to prove the same coincidence in the tax game problems.

11 In the following, when the superscript $h$ is added it indicates per capita. That is, $E g G D P_{i}^{h}=\frac{E g G D P_{i}}{P_{i}}$, for each region $i$.
} 


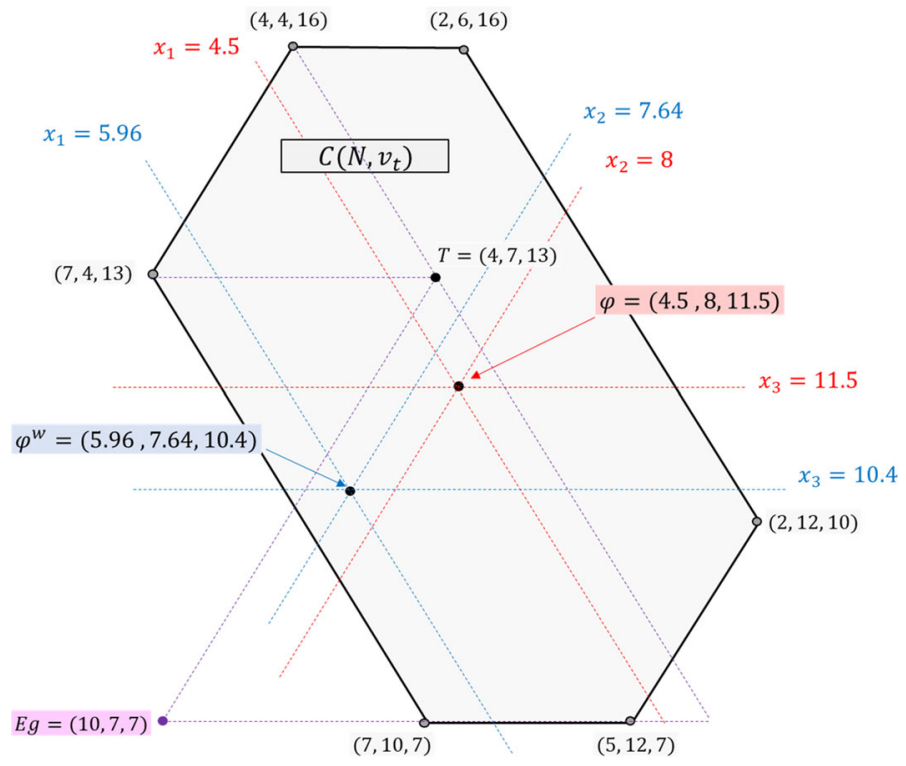

Fig. 2 Close-up of the core

difference between the per capita wealth of region 1 and regions 2 and 3 . The balanced allocation rule yields $\varphi=(4.5,8,11.5)$ as payoffs, and their FBs are $F B(\varphi)=(-0.5,-1,1.5)$. Its associated final $G D P, \varphi G D P=I G D P-F B(\varphi)$, is $\varphi G D P=(10.5,25.5,26.5)$ and the final $G D P$ per capita associated with $\varphi$, $\varphi G D P^{h}=(1.05,3.64,3.79)$. Note that with the balanced allocation $\varphi$ we can obtain a lower effect in the wealth redistribution comparing $E g G D P^{h}$ with $\varphi G D P^{h}$.

To overcome this weakness, we propose a budget allocation that incorporates a certain degree of wealth per capita redistribution in its formulation. To achieve this principle, we consider the differences in the IGDP per capita of the regions when distributing their common fiscal resources. That is, the profits of cooperation $\left(t_{i j}+t_{j i}\right)$ are distributed inversely proportional to the $I G D P^{h}$ of regions $i$ and $j$.

Let be the vector of $I G D P$ per capita of each region, i.e. $I G D P_{i}^{h}=\frac{I G D P_{i}}{P_{i}}$. We define the weighted balanced allocation $\varphi^{w}$ by

$$
\varphi_{i}^{w}(N, R, I)=t_{i i}+\sum_{j \in N \backslash i} \frac{I G D P_{j}^{h}}{I G D P_{i}^{h}+I G D P_{j}^{h}} \cdot\left(t_{i j}+t_{j i}\right), \forall i \in N .
$$

For an alternative interpretation of $\varphi^{w}$, we consider the inverse of $I G D P_{i}^{h}$, that is $\left(I G D P_{i}^{h}\right)^{-1}=\frac{P_{i}}{G D P_{i}}$. We can interpret this inverse as a "normalised population per wealth". Thus, given two regions $i$ and $j$ with the same level of $I G D P$, if $i$ has a population greater than $j$, this means that $i$ is poorer than $j$. Note that 


$$
\frac{I G D P_{j}^{h}}{I G D P_{i}^{h}+I G D P_{j}^{h}} \cdot \frac{\left(I G D P_{i}^{h}\right)^{-1} \cdot\left(I G D P_{j}^{h}\right)^{-1}}{\left(I G D P_{i}^{h}\right)^{-1} \cdot\left(I G D P_{j}^{h}\right)^{-1}}=\frac{\left(I G D P_{i}^{h}\right)^{-1}}{\left(I G D P_{i}^{h}\right)^{-1}+\left(I G D P_{j}^{h}\right)^{-1}}
$$

Therefore, we can define alternatively $\varphi^{w}$ by

$$
\varphi_{i}^{w}(N, R, I)=t_{i i}+\sum_{j \in N \backslash i} \frac{\left(I G D P_{i}^{h}\right)^{-1}}{\left(I G D P_{i}^{h}\right)^{-1}+\left(I G D P_{j}^{h}\right)^{-1}} \cdot\left(t_{i j}+t_{j i}\right), \forall i \in N
$$

Thus, we distribute $\left(t_{i j}+t_{j i}\right)$ between $i$ and $j$ in proportion to their normalised population. We have a parallel result to that of Theorem 2.

Theorem 3 For every tax problem $(N, \boldsymbol{R}, \boldsymbol{I}) \in \mathcal{T}^{N}$, the weighted balanced allocation $\varphi^{w}$ coincides with the weighted Shapley value of the tax game $\left(N, v_{t}\right)$, i.e. $\varphi^{w}(N, \boldsymbol{R}, \boldsymbol{I})=S h^{\omega}\left(N, v_{t}\right)$, where $\omega_{i}=\left(I G D P_{i}^{h}\right)^{-1}$, for all $i \in N$. Moreover, $\varphi^{w}(N, \boldsymbol{R}, \boldsymbol{I}) \in C\left(N, v_{t}\right)$.

The weighted Shapley value was introduced by Shapley (1953a). Although $\varphi^{w}$ is also stable, ${ }^{12}$ it is now closer to the border of the core than $\varphi$. However, what it loses in stability, it gains in a greater degree of interregional solidarity.

We also compute $\varphi^{w}$ in our example. We only show the calculations for region 1.

$$
\begin{aligned}
\varphi_{1}^{w}= & t_{11}+\frac{w_{2}}{w_{1}+w_{2}}\left(t_{12}+t_{21}\right)+\frac{w_{3}}{w_{1}+w_{3}}\left(t_{13}+t_{31}\right) \\
= & (0.7+0.7+0.2+0.4)+\frac{3.5}{1+3.5}[(0.4+0.6)+(0.6+0.4)] \\
& +\frac{4}{1+4}[(0.6+0.4)+(0.8+1.2)]=5.96
\end{aligned}
$$

Making the same for regions 2 and 3, we find that the vector of weighted balance allocations is equal to $\varphi^{w}=(5.96,7.64,10.4)$. In Fig. 2 we can see $\varphi^{w}$ placed close to the boundary of $C\left(N, v_{t}\right)$ in the direction of $E g$. The final GDP associated with $\varphi^{w}$ is equal to $\varphi^{w} G D P=(11.96,25.14,25.4)$, and the final GDP per capita associated with $\varphi^{w}$ is $\varphi^{w} G D P^{h}=(1.21,3.59,3.62)$. We obtain a greater wealth redistribution with $\varphi^{w}$ than $\varphi$, remaining in the core of the tax game.

\section{Stability measure}

The binary assertion that a budget allocation is stable or not, simply because of the positive or negative sign of its associated excesses, is very limited for the political context we are dealing with. The sign of the excesses does not make it possible to assess the extent to which one spending distribution rule may attract a greater consensus than

\footnotetext{
$\overline{12}$ This is always true because $\varphi^{w}$ is a convex combination of the vertices of the core of the tax game, which is also a convex set.
} 
another among the regions. It would be useful to have a measure of the intensity with which a region (or coalition of regions) accepts/rejects an allocation.

One option might be to measure its distance to the centre of the core of the tax game $\left(N, v_{t}\right)$ (which is precisely $\varphi$ ). This could be done with the help of the $\varepsilon$-core concept, introduced by Shapley and Shubik (1996) and later named by Maschler et al. (1979) (see also Tijs and Driessen 1986). That is, the core $C\left(N, v_{t}^{\varepsilon}\right)$, where $v_{t}^{\varepsilon}(N)=v_{t}(N)$, and $v_{t}^{\varepsilon}(S)=v_{t}(S)+\varepsilon$, for all coalitions $S \neq N$. The least core is the set $C\left(N, v_{t}^{\varepsilon *}\right)$, where $\varepsilon^{*}$ is the highest value (possibly negative) of $\varepsilon$ such that $C\left(N, v_{t}^{\varepsilon}\right) \neq \varnothing$. The case $\varepsilon=0$ corresponds with the original game $v_{t}$. A tax allocation is $\varepsilon$-stable if it belongs to the $\varepsilon$-core. As $\varepsilon$ grows, the set $C\left(N, v_{t}^{\varepsilon}\right)$ decreases to the least core. The degree of stability of an allocation will be the highest value of $\varepsilon$ compatible with being $\varepsilon$-stable, where $\varepsilon^{*}$ is the maximum degree of stability.

The problem with this stability measure is that it is not consistent with the maximum budget allocation that a region aspires to manage if this were the only fiscal authority in charge of its management. This amount is given by the total revenue vector $T$. Clearly, $T_{i}$ is the maximum amount of fiscal resources that region $i$ could raise if it were an independent fiscal authority.

Now, we have two opposite scenarios. On the one side, local authorities are not willing to share any fiscal resources with the rest of the regions. On the other side, local representatives are willing to negotiate regarding the total of their common fiscal resources. Between these two extremes, we can specify the $\alpha$ proportion, $\alpha \in$ $[0,1]$, of their common resources that they are not willing to share. With the help of this parameter $\alpha$ we can obtain the degree of stability of a budget allocation $\psi$. This normalised index is a measure based on willingness to share their common tax resources. Moreover, this normalisation also allows us to make comparisons on the stability of spending rules between different countries, or to see the evolution that a rule has undergone over time.

To do this, we define the extended tax game $v_{t}^{\alpha}$ as follows

$$
v_{t}^{\alpha}(S)=\sum_{i \in S} \sum_{j \in S} t_{i j}+\alpha \sum_{i \in S} \sum_{j \in N \backslash S}\left(R_{i j}+I_{j i}\right), \forall S \subseteq N
$$

This amount is the total tax revenues that the coalition of regions $S$ collects within $S$, plus a proportion $\alpha$ of the tax revenue that comes from their commercial relationships with the remaining regions $N \backslash S$. It is the minimum amount $S$ should get to be willing to accept an agreement on the distribution of the budget. Therefore, $\alpha=1$ corresponds to the full sovereignty approach where $v_{t}^{1}(S)=\sum_{i \in S} T_{i}$. Conversely, $\alpha=0$ corresponds to our original shared sovereignty approach of Sect. 2, $v_{t}^{0}(S)=v_{t}(S)$.

Now, for each value of parameter $\alpha$, we qualify as $\alpha$-stable those allocations in the core of $v_{t}^{\alpha}$, i.e. a budget allocation $\psi$ is $\alpha$-stable if $\psi \in C\left(N, v_{t}^{\alpha}\right)$. As, by construction, it holds that $v_{t}^{\alpha}(S) \leq v_{t}^{\alpha^{\prime}}(S)$ for all $\alpha \leq \alpha^{\prime}$, it follows immediately that $C\left(N, v_{t}^{\alpha^{\prime}}\right) \subseteq$ $C\left(N, v_{t}^{\alpha}\right)$. Therefore, to the extent that regions reduce the proportion of common tax resources they are willing to share with each other, the set of $\alpha$-stable budget allocations is reduced. 
Given a budget allocation $\psi$, the lower the value $\alpha$ for the excess of coalition $\mathrm{S}$ to be zero, i.e. $e_{\alpha}(S)=\sum_{i \in S} \psi_{i}-v_{t}^{\alpha}(S)=0$, the greater the amount of shared resources that coalition $S$ has transferred to $N \backslash S$ to obtain $\psi$. Accordingly, for every coalition $S$ and budget allocation $\psi$, we define $\alpha_{S}(\psi)$ as the value of $\alpha$ such that $e_{\alpha}(S)=0$. Thus, $\alpha_{S}(\psi)$ is the $\alpha$ threshold beyond which a coalition $S$ obtains a positive excess in the game $v_{t}^{\alpha}$. Therefore, $\alpha_{S}(\psi)=1$ means that $S$ has not had to give to $N \backslash S$ any amount of fiscal resources to obtain $\psi$, that is $\sum_{i \in S} \psi_{i}=\sum_{i \in S} T_{i}=v_{t}^{1}(S)$. A value $\alpha_{S}(\psi)>1$ implies that, even with all its fiscal resources at its disposal, $S$ could not achieve a budgetary expenditure equivalent to that obtained in $\psi$. Therefore, the bigger $\alpha_{S}(\psi)$ is, the happier $S$ will be with what was obtained in $\psi$. In summary, from the point of view of the full sovereignty approach, low values of $\alpha_{S}(\psi)$ will imply a greater reluctance of $S$ to accept $\psi$. Thus, we will define the degree of stability of a budget allocation $\psi$ as the highest value of $\alpha$ compatible with being $\alpha$-stable, and it will be denoted by $\alpha(\psi)$. The lower its value, the more unstable the budget allocation.

What about the existence of $\alpha$-stable allocations? We find again that its core is always non-empty.

Theorem 4 For every tax problem $(N, \boldsymbol{R}, \boldsymbol{I}) \in \mathcal{T}^{N}$, the core of its associated tax game $\left(N, v_{t}^{\alpha}\right)$ is non-empty for every $\alpha$ in $[0,1]$.In particular, $T \in C\left(N, v_{t}^{\alpha}\right)$.

Note that when $\alpha=1$, the allocation $T$ is the unique stable allocation in the game $\left(N, v_{t}^{1}\right)$, that is $C\left(N, v_{t}^{1}\right)=\{T\}$. This happens because $v_{t}^{1}$ is an additive ${ }^{13}$ characteristic function.

We have seen that the balanced allocation $\varphi$ is in the centre of $C\left(N, v_{t}^{0}\right)$. It is the most stable allocation for the $\alpha=0$ scenario. As far as $\alpha$ increases, the set of $\alpha$-stable allocations $C\left(N, v_{t}^{\alpha}\right)$ reduces. The balanced allocation $\varphi$ will therefore be unstable for some critical value of $\alpha$. Moreover, this threshold value will depend on the data of each tax problem; however, it is possible to find a bound for $\alpha$ which guarantees that $\varphi$ remains $\alpha$-stable in any tax problem, as the following theorem shows.

Theorem 5 For every tax problem $(N, \boldsymbol{R}, \boldsymbol{I}) \in \mathcal{T}^{N}$, the balanced allocation rule is $\alpha$-stable for all $\alpha \leq 1 / 2$.

We will again use the numerical example introduced in Sect. 2 to illustrate these new concepts. Now, the extended tax game $\left(N, v_{t}^{\alpha}\right)$ is given by

$$
\begin{aligned}
& v_{t}^{\alpha}(1)=2+2 \alpha, v_{t}^{\alpha}(2)=4+3 \alpha, v_{t}^{\alpha}(3)=7+5 \alpha, v_{t}^{\alpha}(\{1,2\})=8+3 \alpha, \\
& v_{t}^{\alpha}(\{1,3\})=12+5 \alpha, v_{t}^{\alpha}(\{2,3\})=17+3 \alpha, v_{t}^{\alpha}(\{1,2,3\})=24 .
\end{aligned}
$$

To see the inequalities that satisfy any $\alpha$-stable allocation $x$, note that, for region 1 it must hold that $x_{1} \geq v_{t}^{\alpha}(1)=2+2 \alpha$, and for regions 2 and 3 that $x_{2}+x_{3} \geq$ $v_{t}^{\alpha}(\{2,3\})=17+3 \alpha$, which jointly with $\sum_{i \in N} x_{i}=v_{t}^{\alpha}(\{1,2,3\})=24$, implies that $x_{1} \leq v_{t}(N)-\sum_{i \in N} x_{i}=24-(17+3 \alpha)=7-3 \alpha$. Following the same reasoning for regions 2 and 3 , we obtain that the core of the game $\left(N, v_{t}^{\alpha}\right)$ is given by the set

$$
C\left(N, v_{t}^{\alpha}\right)=\left\{\begin{array}{c}
\left(x_{1}, x_{2}, x_{3}\right) \in \mathbb{R}^{3}: 2+2 \alpha \leq x_{1} \leq 7-3 \alpha ; 4+3 \alpha \leq x_{2} \leq 12-5 \alpha \\
7+5 \alpha \leq x_{3} \leq 16-3 \alpha
\end{array}\right\}
$$

$\overline{13}$ That is, $v_{t}^{1}(S)=\sum_{i \in S} T_{i}$ for all $S \subseteq N$. 


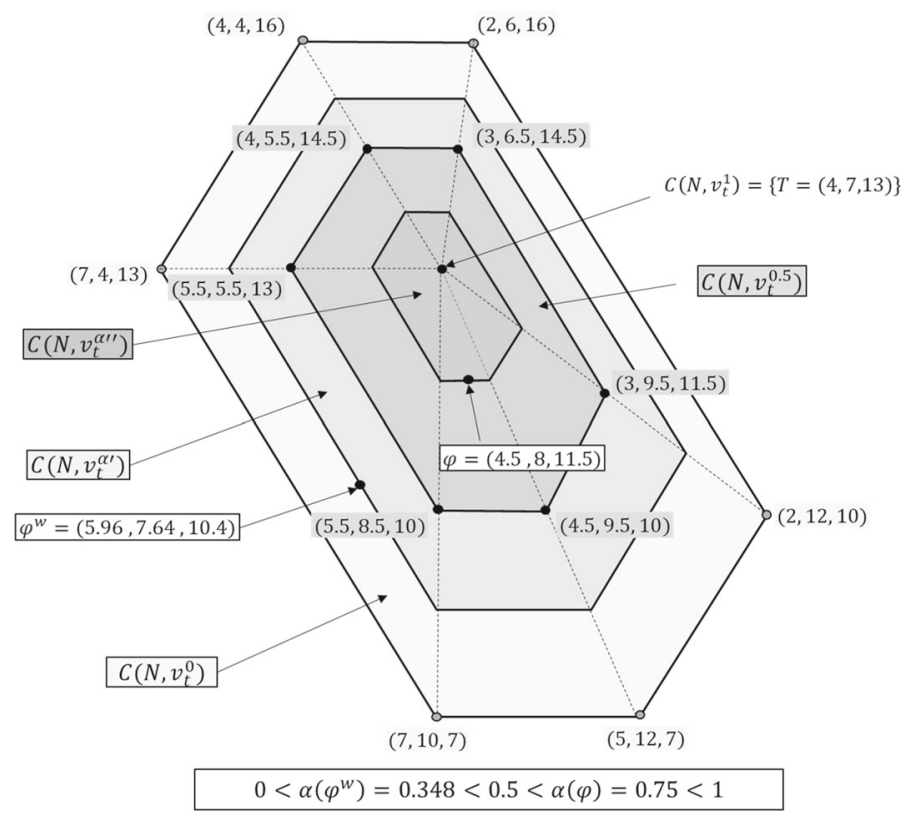

Fig. 3 Core representation for some values of $\boldsymbol{\alpha}$

In Fig. 3 Core representation for some values of we draw the core of the cooperative tax game $\left(N, v_{t}^{\alpha}\right)$ for some values of $\alpha$. We can see that the degree of stability of $\varphi$ and $\varphi^{w}$ is $\alpha\left(\varphi^{w}\right)=0.384$ and $\alpha(\varphi)=0.75$. In general, we can conjecture that the greater the differences in the per capita wealth among regions, the lower $\alpha\left(\varphi^{w}\right)$.

In practice, calculating the excesses of all coalitions is not a feasible task. ${ }^{14}$ Nevertheless, we can calculate at least the individual excess of each region. In the following, we denote by $\zeta_{i}^{\alpha}$ the individual regional value of $i$ in the tax game $v_{t}^{\alpha}$. That is,

$$
\zeta_{i}^{\alpha}(N, \boldsymbol{R}, \boldsymbol{I})=v_{t}^{\alpha}(i)=t_{i i}+\alpha \sum_{j \in N \backslash i}\left(D_{i j}+I_{j i}\right), \forall i \in N
$$

It is obvious that $\zeta_{i}^{1}(N, \boldsymbol{R}, \boldsymbol{I})=T_{i}$. For any budget allocation $\psi$, and region $i$, the threshold $\alpha_{i}(\psi)$ is the value of $\alpha$ for which $\zeta_{i}^{\alpha}(N, \boldsymbol{R}, \boldsymbol{I})=\psi_{i}(N, \boldsymbol{R}, \boldsymbol{I})$. Equivalently, $\alpha_{i}(\psi)$ is the value for which the individual excess of región $i$ is zero. For values of $\alpha$ less than $\alpha_{i}(\psi)$ the budget allocation $\psi$ gives a payoff to $i$ which is not even individually rational, and therefore $\psi$ will not definitely be $\alpha$-stable. ${ }^{15}$

\footnotetext{
14 This is because the calculation time grows exponentially with the number of coalitions, which is $2^{n}-1$.

15 Of course, this definition can also be applied to any coalition.
} 


\subsection{Discussion of the interpretation of $v_{t}^{\alpha}$}

We wish to stress that we should discard the use of the tax game $v_{t}$ as a tool to estimate the economic consequences under a secession process in terms of the amount of fiscal resources that a region, or a group of regions, would obtain at the end of secession. Under our approach, it simply gives us an estimate of the amount of fiscal resources over which a coalition of regions is sovereign, differentiating them from those of shared sovereignty with all regions, irrespective of what one may suspect will be the case in the event of secession. The excess in a tax game is therefore only a tool for the public budget spent in a region.

If one wishes to consider what could happen after a secession process, the very pessimistic calculus of $v_{t}^{0}(S)$ gives a poor idea of the economic consequences of such rupture. This is because we have excluded all commercial relationships between regions $S$ and $N \backslash S$ in its calculus. In a secessionist scenario we can expect that some trade activity would remain after the breakdown, to a greater or lesser extent. What would economic activity be like following a rupture within the country? There are too many factors to consider, each with a high degree of uncertainty. We can mention some of them here.

Any hypothetical breakdown scenario that we can imagine will certainly restrict the commercial relationships between the secessionist and the rest of the regions that remain in the country. This is the well-known border effect. ${ }^{16}$ It establishes that domestic agents trade more with each other than with foreign agents of the same size and distance. A classic case study is that of US-Canadian trade. McCallum (1995) and Helliwell (1996) show that the interprovincial trade between Canadian provinces was more than 20 times larger than trade between Canadian provinces and American states in the period 1988-1990. This is a remarkable effect because both states have low custom tariffs, phased out by the 1988 Free Trade Agreement. In the European Union, Head and Mayer (2000) found that Europeans purchased 14 times more from domestic producers than from equally distant ones, for the average industry in 1985 (tariffs and quotas within the EU phased out by 1968).

The range of assumptions made to determine the intensity in this border effect can range from a fully amicable process to a much more traumatic one. For example, Fidrmuc and Fidrmuc (2003) have studied some cases of disintegration in the former Eastern Bloc. They found evidence of a high level of economic integration before breakdown, with internal trade exceeding external trade intensity from 24-fold (for Slovenia and Croatia) to 43-fold (the former Soviet Union and Czechoslovakia). Disintegration is followed by a sharp fall in trade intensity. After breakdown, these levels decrease to twofold in the case of Slovenia and Croatia, sevenfold for the former Czechoslovakia, 13-fold for the Baltics, and 30-fold for Belarus, Russia, and Ukraine. However, Djankov and Freund (2002) reported that, between 1994 and 1996, Russian regions traded $60 \%$ more with each other than with former USSR Republics, while there was no significant difference before disintegration. This contrary result supports the hysteresis hypothesis: the tendency for established bilateral trade links to change

\footnotetext{
$\overline{16}$ See Magerman et al. (2016) for a recent and comprehensive review of this phenomenon.
} 
relatively slowly. De Sousa and Lamotte (2007) show that there is no empirical evidence to suggest that political disintegration favours either a severe fall in trade or a stable flow in commerce.

Apart from the border effect, there are economic aspects in a secessionist process that are specific for each country in question. For example, Spain belongs to the European Union. This political fact implies that a region, which becomes independent, will be out of the EU, at least temporally. Banks could be tempted to change their headquarters to another region in the country to guarantee the financial support of the European Central Bank. Well-established companies in the Spanish and European market could also follow this offshoring process, fearful of losing their market share because of new (unknown) protective custom tariffs, or due to emotional (or rational) boycott campaigns. Such considerations are of an uncertain nature and difficult to assess in advance. Moreover, in each case, the productive structure and the institutional framework will condition the result.

If region $i$ produces a product sold to region $j$, the entire VAT on this product is not necessarily lost in case of secession. The region could try to compensate for these losses by increasing the tax on the product during its production in the home region. This will increase their price decreasing their demand. The demand elasticity for the product will determine the ultimate tax effect. Once again, some legal rigidities (such as remaining the EU or not) could restrict freedom for such manoeuvres.

In short, estimating a priori what the economic outcome of a region will be after a process of secession, although intellectually attractive, is not worthwhile for our practical purposes. For example, we could estimate what might happen if Catalonia separated from the rest of Spain, and then, once we have obtained a rough estimate of what could happen, carry out a rational cost-benefit analysis to find out if it is worth trying to achieve independence. For that purpose, we must compare alternative scenarios. First, we should establish whether the rupture is agreed or taken unilaterally. In the latter case, specify the kind of reaction that we can expect from Spain, with or without the use of force, and specify to what extent Catalonia would obtain international recognition as a state, particularly by the EU. Finally, specify the intensity of the border effect in each of these possible options. This means that we must estimate the corresponding matrix of interregional trade for all possible scenarios.

In summary, there are too many parameters, all uncertain, and perhaps moving in opposite directions, to try to predict what might indeed come about. ${ }^{17}$ We believe that summarising all these parameters in a single optimistic/pessimistic parameter $\alpha$, so that $v_{t}^{\alpha}$ is an acceptable linear approximation, does not seem like a good idea.

\section{Spanish case}

We apply the theory developed in Sect. 2 to the Spanish case. We use fiscal data from 2011 to 2014, obtained from the System of Territorialised Public Accounts (SCPT)

\footnotetext{
17 Even if we insist on doing so, we will have to repeat this exercise for all possible coalitions, if we want to get $v_{t}$. In Spain there are $18 \mathrm{ACs}$, so we will have to repeat that estimate $2^{18}-1$ times, in the EU, $2^{28}-1$ times, or in the USA, $2^{50}-1$ times, which in practical terms is an unfeasible task.
} 
website of the Spanish Ministry of Finance and Public Administration. ${ }^{18}$ The data for the inter-regional trade is provided by the CEPREDE Economic Prediction Centre, in the C-interg project. ${ }^{19}$ The data for foreign imports and exports provided by the Spanish Ministry of Industry, Commerce and Competitiveness, is available on the Datacomex website. ${ }^{20}$ The analysis focuses on the year 2014. The results for 2011, 2012, and 2013 are very similar and can be downloaded in the TaxFederalism.xlsx ${ }^{21}$ Excel file.

At this point, note that there are different methodological approaches to the calculation of FBs, related to who pays the taxes and who benefits from them. Scholars mainly use two methodologies: the burden-benefit incidence approach and the monetary flow approach. ${ }^{22}$ The two methodologies could give different FBs for some regions, so the results may vary depending on the approach used. Broadly, the burden-benefit approach allocates income to the territory where those that ultimately bear the tax burden reside and imputes the expenditure to the territory where those that benefit from the public services or public transfers they finance reside. Conversely, the monetary flow approach imputes tax revenues to the territory where the economic capacity subject to taxation is located, non-tax revenues to the territory where payment takes place, and expenses to the territory where the expenditure on goods and services, or distribution operations take place.

Both approaches measure different issues. The burden-benefit approach calculates the difference between what residents of a region contribute to and receive from all public institutions. Its goal is the evaluation of equity in the redistributive effects of public sector action. The monetary flow approach assesses the effects of public sector action on economic activity in a given territory, determining how its economic aggregates vary in terms of production and consumption, and the public revenues and payments located in each territory. The resulting balance outlines the effects of public sector income and expenditure on the economic activity of each territory, irrespective of the residence of those who bear the burden and of those who obtain the benefits.

We illustrate both approaches by means of a simple example. Let us consider military spending on defence. In this case, the beneficiaries are all residents of the national territory. Suppose $K$ is the total national defence expenditure, and $K_{i}$ is the actual expenditure in region $i . P$ is the total population, and $P_{i}$ is the population of region $i$. If we are interested in measuring the impact on the GDP of region $i$ which has allocated public funding to defence, we should use $K_{i}$, that is the amount imputed by the monetary flow approach. However, if we want to measure the benefit of being part of the union obtained by the residents of region $i$, as a result of the total defence expenditure, we must use $K \cdot \frac{P_{i}}{P}$. Alternatively, if region $i$ would like to cover its own defence expenditure, it should make a contribution in accordance with its population

\footnotetext{
18 http://www.hacienda.gob.es/es-ES/CDI/Paginas/OtraInformacionEconomica/Sistema-cuentasterritorializadas.aspx.

19 https://www.c-intereg.es/en/annual-database.

20 http://datacomex.comercio.es/principal_comex_es.aspx.

21 https://www.uv.es/ecalvo/TaxFederalism.xlsx.

22 A good introduction to this topic is in IEB's Report on Fiscal Federalism and Public Finance 14 (2015).
} 
size, ${ }^{23}$ that is $K \cdot \frac{P_{i}}{P}$. This is the amount charged following the burden-benefit approach. These amounts, $K_{i}$ and $K \cdot \frac{P_{i}}{P}$, can be quite different from each other.

The FBs given in the SCPT follow only the burden-benefit approach, and we follow the same approach in the present work. ${ }^{24}$ We believe it is more appropriate to measure the difference between what the union brings to the residents of a region, and the expenses they make to obtain it, either within the union, or if they were an independent entity.

Spain has 17 autonomous communities (AC) and two autonomous cities (Ceuta and Melilla). Both are merged into a single element in the SCPT. The present public budget spent in each AC will be called the Spanish rule $S p$. Total expenditures are greater than total tax revenues, generating a budget deficit for these years. We therefore adjust the revenues in such a way that the total net balance will be zero. In this way, we replace real flows by "neutralised" flows. For such an operation, we distribute the deficit among the ACs in proportion to their population.

We only make a summary description of the items in the SCTP accounts. The aggregates of total public revenues in the SCPT are as follows:

(1) Direct taxes (taxes on personal income, corporate income, on non-resident income, inheritance and donations, wealth, environmental, deposits of credit institutions).

(2) Indirect taxes (VAT, excise duties, electricity, certain means of transport, external traffic, insurance premiums, transfers of assets and legal acts, mineral oils, gambling taxes, fluorinated gases).

(3) Taxes and municipal fees.

(4) Social security contributions.

(5) Other central administration revenues (fees, public prices and revenues from the sale of goods and services of the central administration, $\mathrm{CNMV}^{25}$ fees, $\mathrm{CNMC}^{26}$ fees, financial and patrimonial revenues, Bank of Spain revenue).

Table 1 shows the main aggregates of the $2014 \mathrm{FBs}^{27}$. The revenues assigned to consumption are indirect taxes. We have grouped them in column $I=(2)$. We assign the rest of the income to the production of goods and services. We have grouped them in the column of direct revenues $\mathrm{R}=(1)+(3)+(4)+(5)$. The total revenues will be $\mathrm{T}=\mathrm{I}+\mathrm{R}$. Column $\mathrm{D}$ is the territorial distribution of the deficit, and the adjusted income column AT is the sum of the revenues plus the deficit, $\mathrm{AT}=\mathrm{T}+\mathrm{D}$. We group the total public expenditure in the Sp column.

We will use gross domestic product $(G D P)$ as a reference for the level of wealth of a region. To measure the redistributive effect of the current spending rule on GDP,

\footnotetext{
23 If not more, due to economies of scale resulting from sharing costs with other regions.

24 The reader can find a detailed explanation of the methodology followed in the building of the SCTP in De la Fuente et al. (2014).

25 National Stock Market Commission.

26 National Commission for Markets and Competition.

27 The data of population considered in SCPT does not coincide with the real data. Instead, it adjusts them in order to compensate for some geographical and demographic differences between regions. This makes the cost of producing some public goods different among some ACs. For example, there are differences in road network maintenance in a rural region compared with more urban regions. Population adjustments try to capture all these factors.
} 


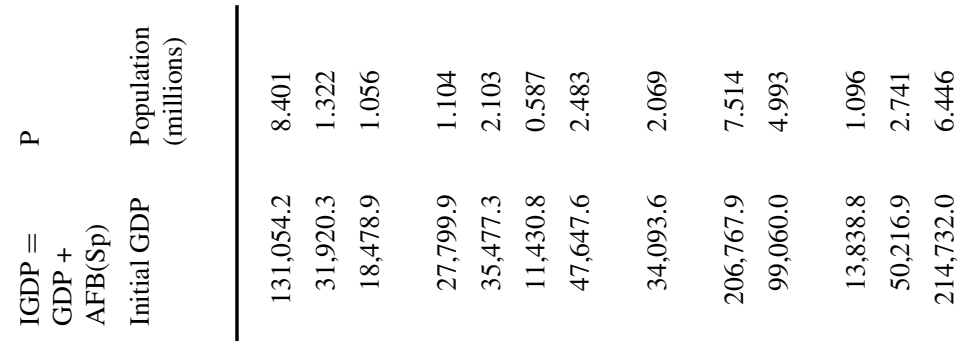

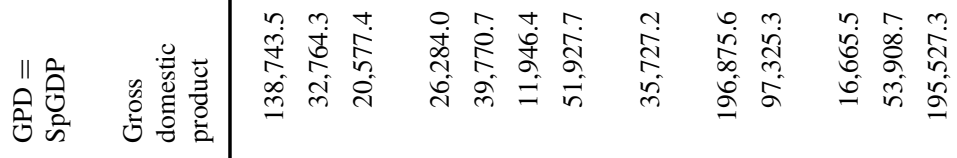

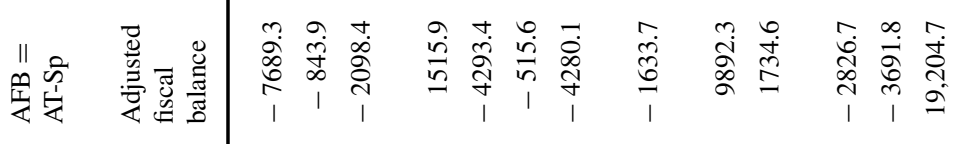

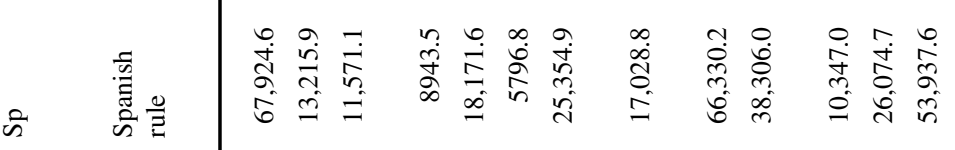

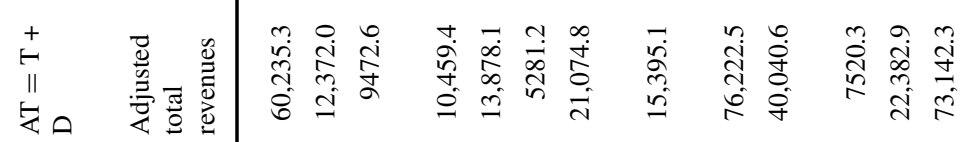

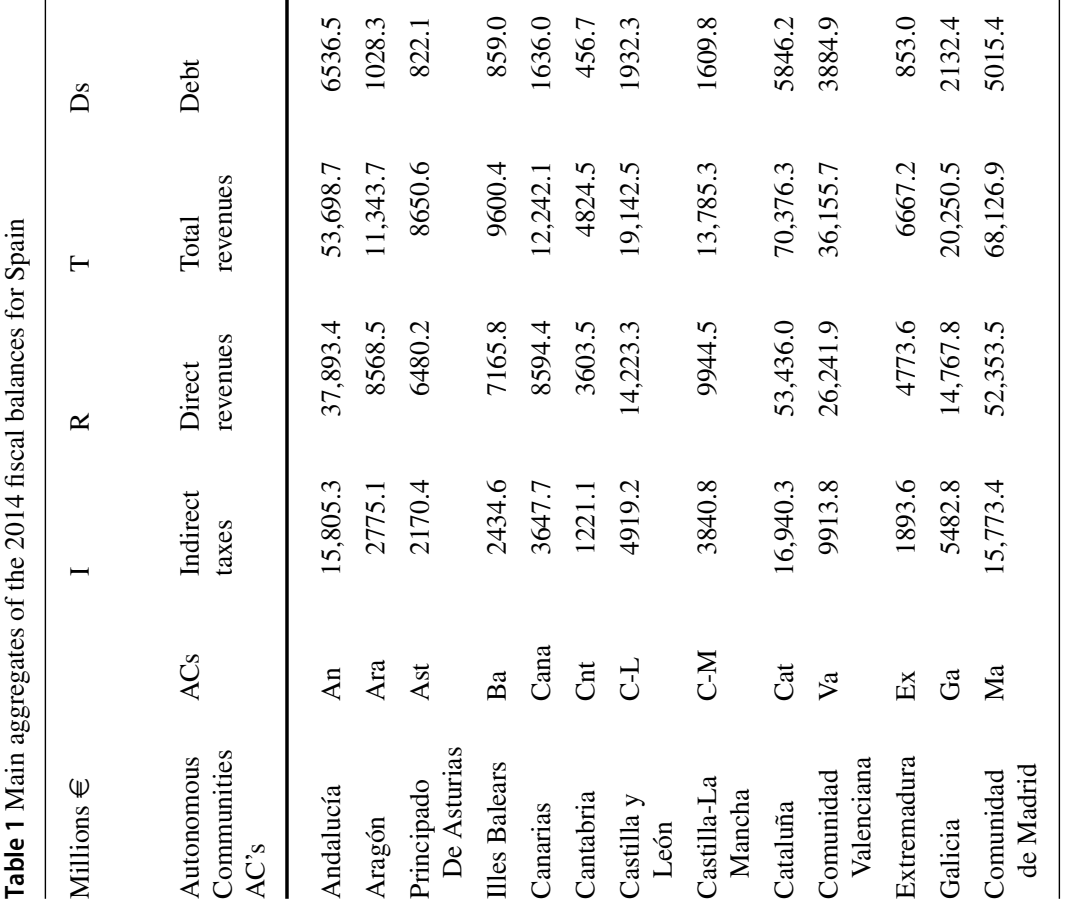

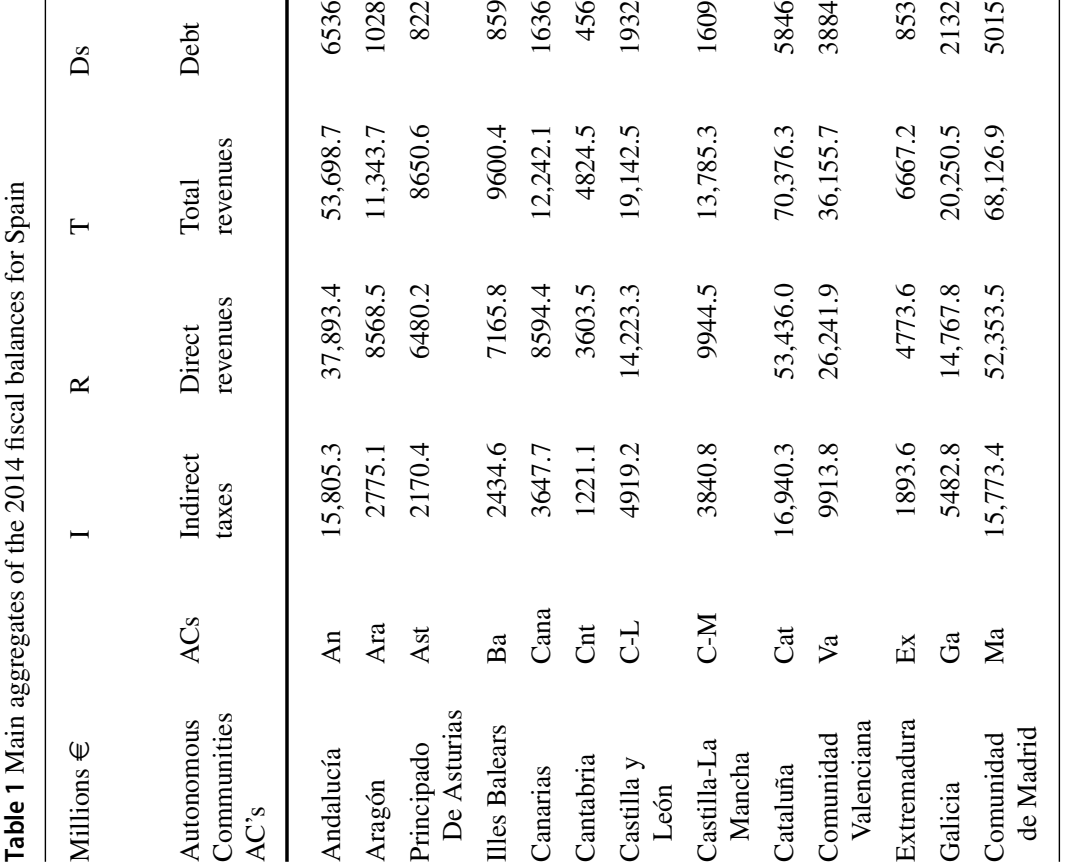

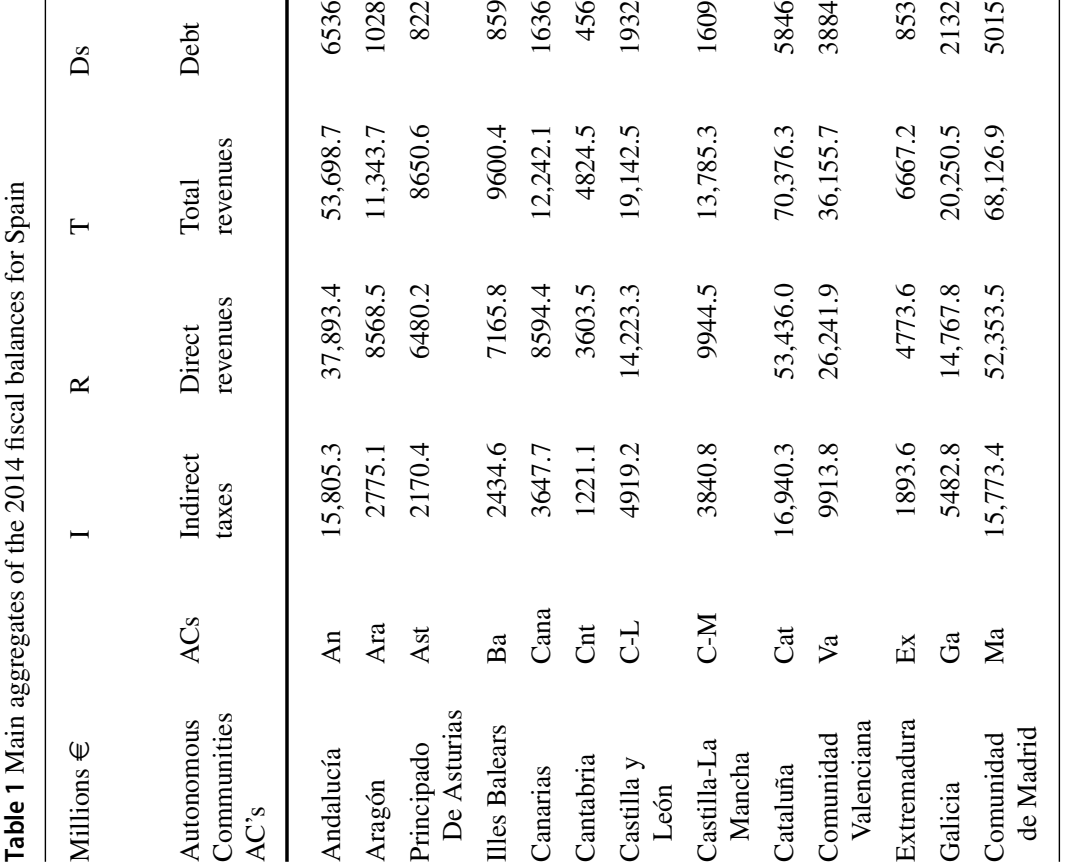

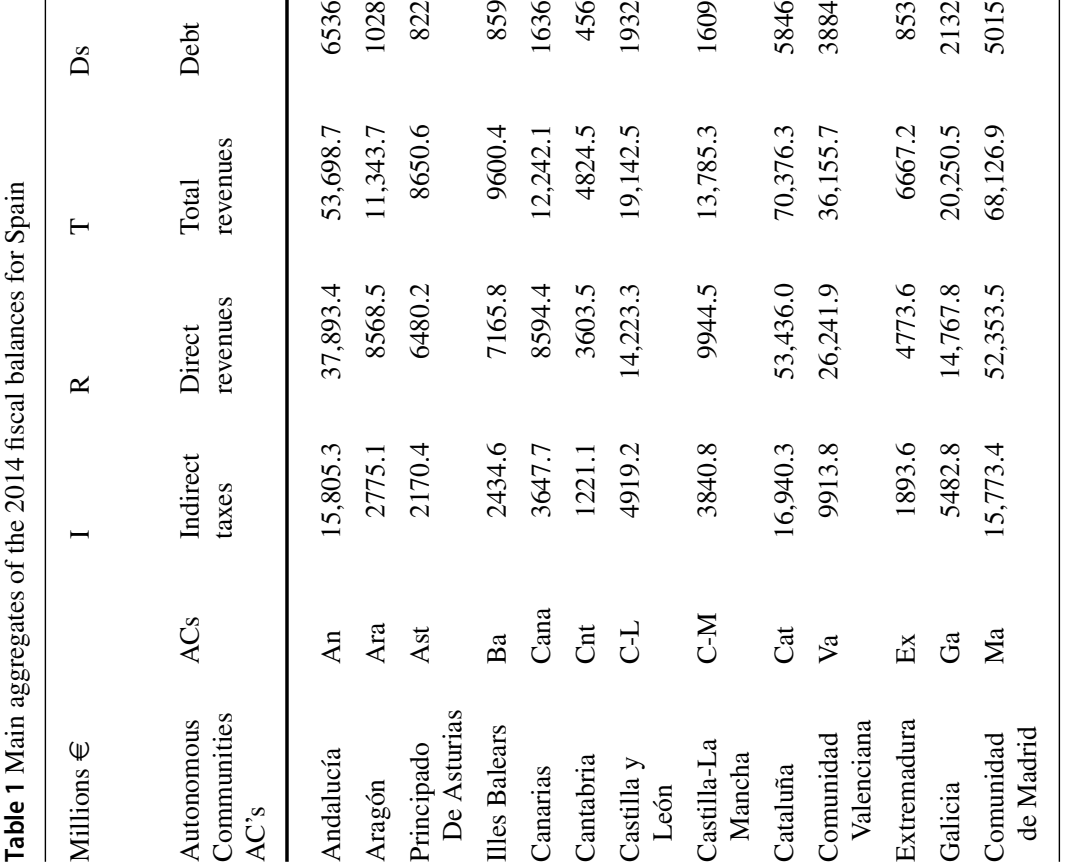

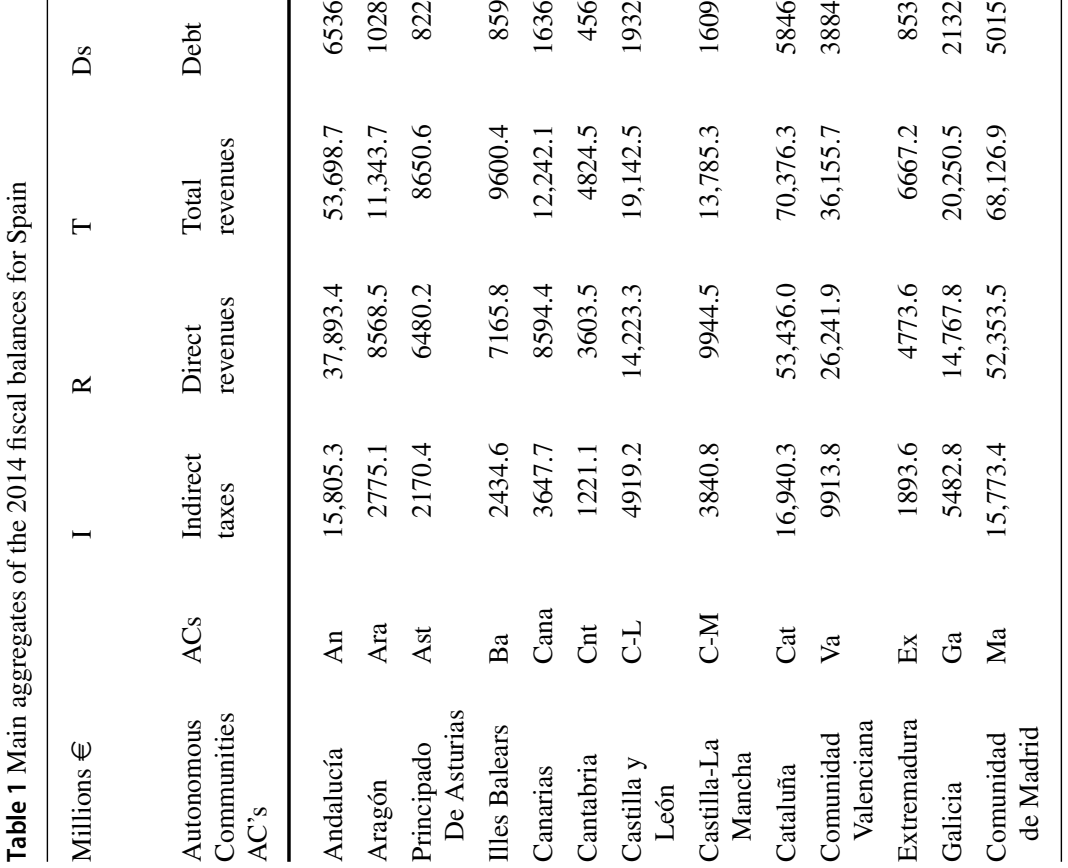




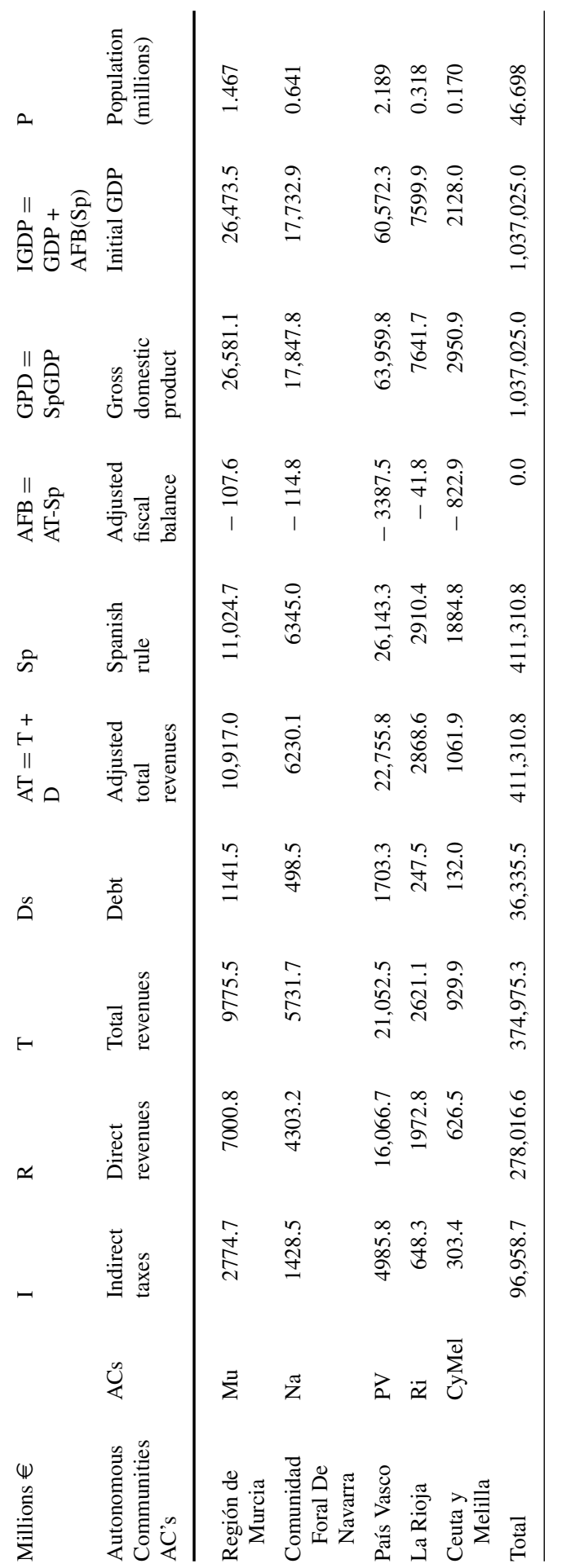


or if we want to compare the effects of alternatives rules, we calculate what the initial $G D P$ of each region would be without the transfers originated by the current rule. This is what we call Initial GDP (see Eq. (6)):

$$
I G D P_{i}=S p G D P_{i}+A F B_{i}(S p), \forall i \in N .
$$

We denote the final GDP associated with any other budget allocation rule $\psi$ by $\psi G D P$, and it is equal to the initial GDP minus the fiscal balance associated with it, that is, the payoffs given by the rule $\psi$ to the region minus the adjusted total tax revenues of the region, hence:

$$
\psi G D P_{i}=I G D P_{i}-A F B_{i}(\psi)=I G D P_{i}-\left(A T_{i}-\psi_{i}\right), \forall i \in N
$$

Now, we can compare the initial GDP per capita with the GDP per capita associated with the Spanish rule $S p$. We show this data in Table 2, and we have added the Spanish per capita budget allocation, $S p^{h}=S p / P$. We sorted the ACs ranked by their $I G D P$ per capita, $I G D P^{h}$. The Spanish average is $€ 22,207$. Decreasing values have been highlighted in italics.

At first glance, the Spanish tax rule has some clear redistributive effects. In general, $G D P$ per capita increases in regions where $I G D P^{h}$ is lower than average. The gap between the minimum and maximum value of the $G D P^{h}$ is reduced, passing the value range between $€ 12,543$ and $€ 33,314$ to $€ 15,201$ and $€ 30,334$. We can also see the redistributive effect of $S p$ in the slope of the regression line of the graphic which relates the initial $I G D P^{h}$ and the $S p G D P^{h}$. A positive slope of less than one means a redistributive effect: a lower slope implies a greater degree of redistribution. The lower the slope, the greater the degree of wealth redistribution (Fig. 4).

It is clear that $S p$ has an overall positive redistributive effect, as the slope of its regression line is less than $1(0.769)$. However, this rule has some questionable results.

On the one hand, consider the case of the Comunidad Valenciana $(V a)$, whose $I G D P^{h}=€ 19,841$ is lower than average. Surprisingly, after the wealth redistribution caused by $S p$, however, its per capita wealth decreases to $\operatorname{Sp} G D P^{h}=€ 19,493$. On the other hand, some regions whose $I G D P^{h}$ are above average, end up with a $S p G D P^{h}$ even higher than their own $I G D P^{h}$ : they are $\{R i, A r a, N a, P V\}$. The per capita expenditure $S p^{h}$ of each region also does not follow a specific pattern. Regions with a $I G D P^{h}$ below the average have an expenditure $S p^{h}$ that is also below the average: $\{M u, V a, A n, C-M, C a n a\}$. Furthermore, regions with an above average $I G D P^{h}$ also have a $S p^{h}$ above the average: $\{C a t, N a, R i, A r a, P V\}$. Finally, the Spanish rule clearly breaks the ordinality principle (the redistributive effect of a rule "should narrow financing disparities across regions without altering their wealth relative ranking"). If

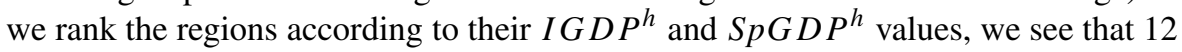
pairs of regions exchange their relative position.

$$
\left\{\begin{array}{c}
(C y M e l, E x),(C y M e l, A n),(C y M e l, C-M),(C a n a, M u),(A s t, M u),(G a, V a), \\
(C-L, C n t),(C-L, V a),(C n t, V a),(R i, B a),(A r a, B a),(P V, N a)
\end{array}\right\}
$$




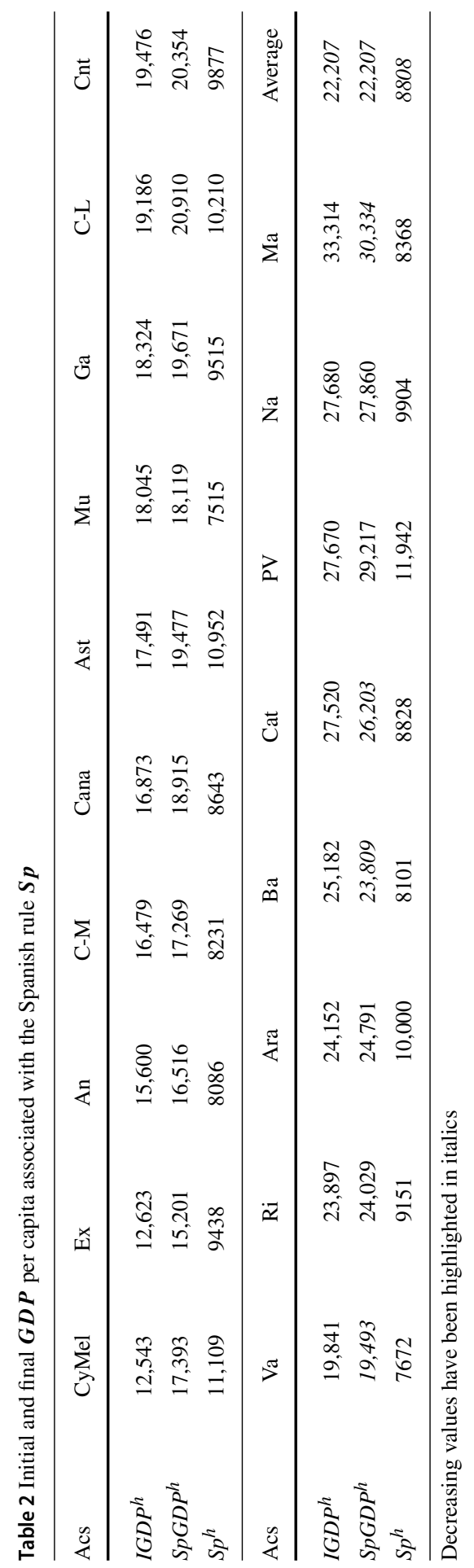




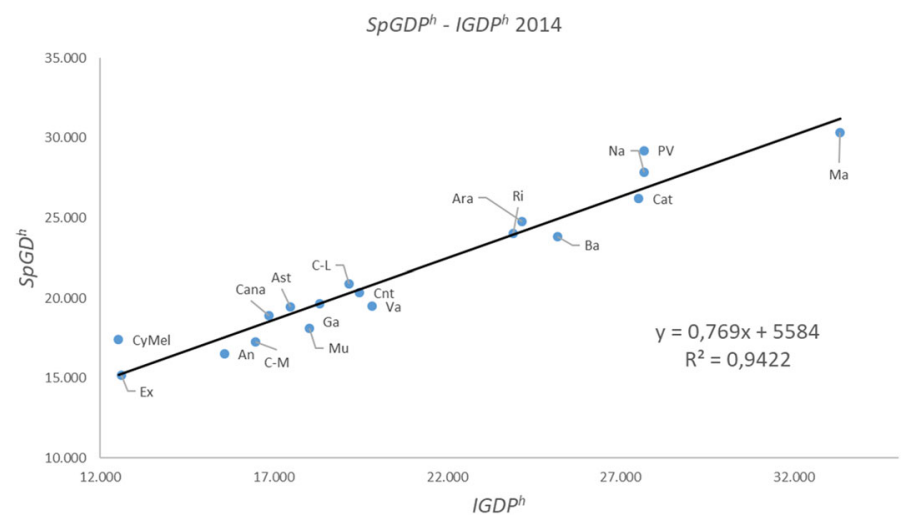

Fig. 4 Redistributive effects of the Spanish rule $S p$

We can also see this fact in Fig. 4. If the ranking is not altered, the points will be placed on the regression line, and dispersion will be null $\left(R^{2}=1\right)$. A greater dispersion (lower values of $R^{2}$ ) corresponds to a greater number of alterations in the ranking.

In summary, we can see that the results of the current Spanish rule in terms of equity, ordinality, and distribution of wealth seem, at the very least, quite arbitrary. We can explain this by the fact that, instead of being the result of the systematic application of a set of clear and transparent principles, it has been the product of successive negotiations over time between national political parties and small nationalist leaning parties.

What can we say about the stability of $S p$ rule, from the point of view of the tax game $\left(N, v_{t}\right)$ ? In the rest of this section, we will see that the $S p$ rule is located quite close to the area we have qualified as unstable.

The first step is to build the Spanish tax game $\left(N, v_{t}\right)$. For that purpose, we use the matrix of the commerce inter-regional trades provided by the c-interg project institution. Unfortunately, the trade matrix only provides data for goods, and therefore, we also need to complete it for services. The National Institute of Statistics ${ }^{28}$ on the INEbase website provides this regional data on services. The statistics supply the data aggregated by CAs only. To make a territorial distribution of sales of services we will follow the same distribution as that provided for goods. At the national level only $13 \%$ of total services are destined for export, and therefore we will reduce the services distributed in each region by $87 \%$. In this way, we obtain an estimated approximation of the matrix $\boldsymbol{C}$ of interregional exchanges, exports and imports for the Spanish economy. We give these values in Table 9 in the "Appendix". We have added the values of the average types $\tau_{i}^{R}$ and $\tau_{i}^{I}$. Once $\boldsymbol{C}$ is obtained, we can calculate matrices $\boldsymbol{I}$ and $\boldsymbol{R}$. We give matrix $\boldsymbol{I}$ in Table 8 and matrix $\boldsymbol{R}$ in Table 7 in the "Appendix".

Recall that the excess of $S$ in the $S p$ tax rule is the difference between the total public resources collected in $S$ (excluding all those derived from trade with the other

\footnotetext{
28 http://www.ine.es/dyngs/INEbase/es/operacion.htm?c=Estadistica_C\&cid=1254736176865\&menu= resultados\&dp=1254735576778.
} 
regions) and the public expenditure incurred in $S$, that is $e(S)=v_{t}(S)-\sum_{i \in S} S p_{i}$. Under our approach, $v_{t}(S)$ is the amount of fiscal resources that $S$ is not willing to share with the remaining regions $(N \backslash S)$ of the country. A positive excess, or very close to it, may therefore support a higher degree of disappointment against the distribution of resources obtained in $S p$ by $S .^{29}$

In principle, we have to say that we have not found any region, or coalition of regions with a positive excess ${ }^{30}$ in the Spanish case. For example, Catalonia, which has high secessionist aspirations, has a negative excess of

$$
e\left(\{C a t\}, S p, v_{t}\right)=€-9382 \text { million }
$$

If we consider the set of "Catalan Countries", formed by Catalonia ( $\mathrm{Cat}$ ), Valencia $(V a)$, and Balearics $(B a)$, its excess is also negative

$$
e\left(\{C a t, V a, B a\}, S p, v_{t}\right)=€-11,952 \text { million }
$$

Finally, the group of "foral communities", formed by the Basque Country $(P V)$ and Navarre $(\mathrm{Na})$, which also have high secessionist aspirations, has a negative excess:

$$
e\left(\{P V, N a\}, S p, v_{t}\right)=€-10,780 \text { million }
$$

This is undoubtedly a surprising result. Spain is a country with great differences in wealth across its regions. Looking at the $I G D P$ per capita, the AC of Madrid $(\mathrm{Ma})$ is 2.66 times richer than the AC of Ceuta and Melilla $(\mathrm{CyMel})$. As we have just seen, in general, the $S p$ rule has an acceptable degree of inter-regional solidarity. It is noteworthy that the income allocation produced by the current Spanish financial system, $S p$, has not caused an unstable distribution; mainly because it was not a goal pursued consciously by those who conceived it. To see how easily an ambitious redistributive target could generate unstable allocations in Spain, we will calculate what we would get if we wanted per capita public expenditure to be the same in all regions. We achieve it with the egalitarian spending rule $E g$.

We can compare the values obtained with $S p$ and $E g$ in Table 3.

Income transfers between regions are very similar: $€ 32,348$ million for $S p$ and $€ 32,288$ million for $E g$; however, the transfer of wealth has a different effect on both allocations. Consider the coalition formed by four of the latter in the ranking of IGDP $P^{h}, S=\{C y M e l, A n, E x, C a n a\}$, an $N \backslash S$ is the set formed by the rest of Spanish regions. The excess for $N \backslash S$ with the Spanish allocation was negative, but nevertheless, the excess with the egalitarian is now positive ${ }^{31}$ :

$$
e\left(N \backslash S, S p, v_{t}\right)=€-74 \text { million }<0 \text {, and } e\left(N \backslash S, E g, v_{t}\right)=€ 2757 \text { million }>0
$$

\footnotetext{
29 And those who think they would really improve their economic well-being if coalition of regions $S$ were an independent entity.

30 Note that the total number of possible coalitions is $2^{18}-1$, and we have not checked all of them.

31 The reader can compute these values easily in the downloadable Excel file TaxFederalism-X-M.xlsx.
} 


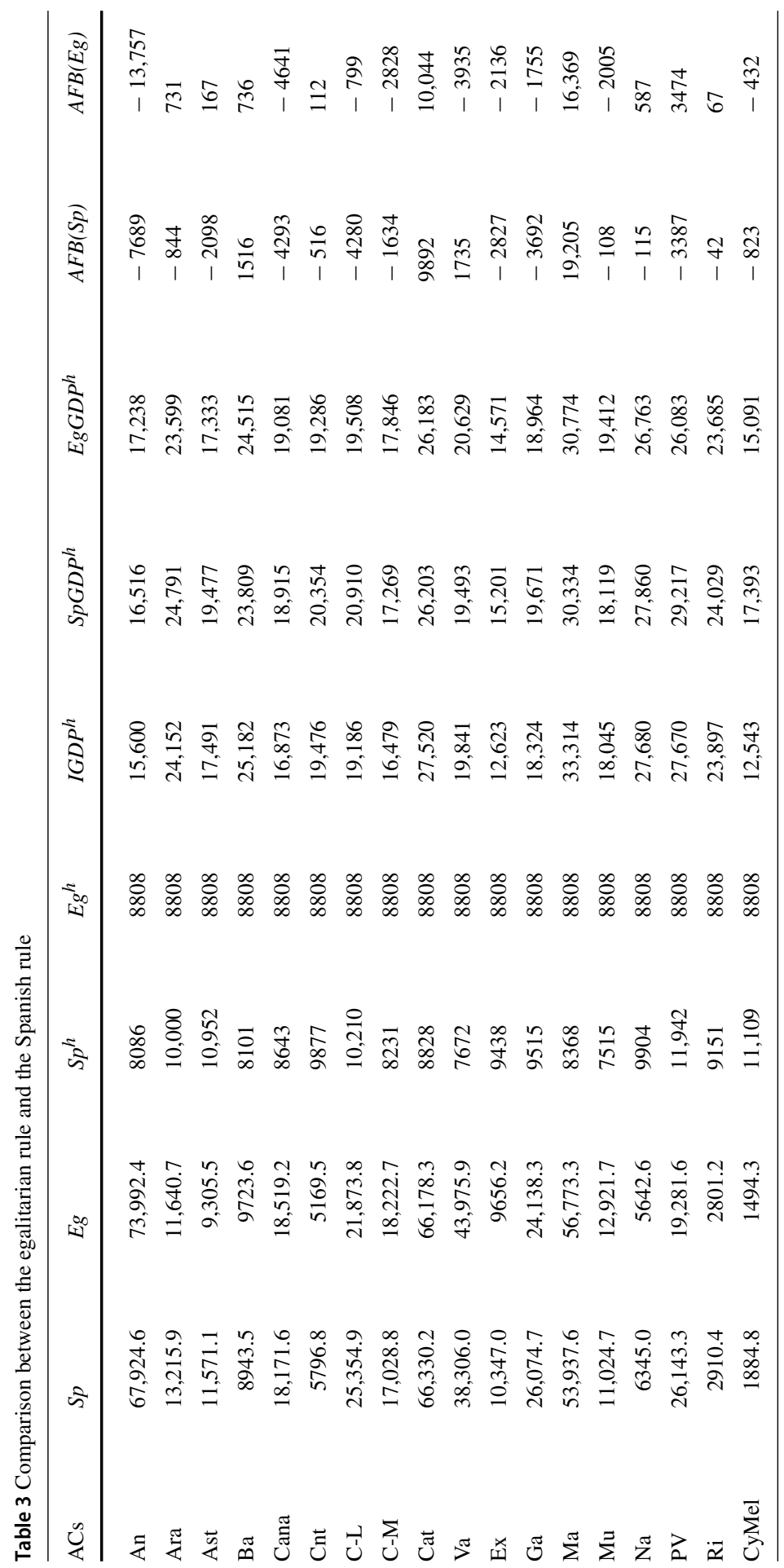


If the $E g$ rule were applied, we can conjecture the emergence of a greater degree of rejection on the part of the rich regions of such budgetary regional distribution.

In view of this, we might think that, despite everything, politicians have not ended up doing so badly in designing $S p$, at least from the point of view of its stability. Unfortunately, this is not so. A closer look shows that $S p$ is certainly quite close to being unstable. After Madrid, the Balearic Islands is the second AC that loses more $I G D P$ per capita when applying $S p(1.373 €$ per capita loss $)$. Accordingly, its regional excess is

$$
e\left(\{B a\}, S p, v_{t}\right)=€-461 \text { million }<0
$$

This is a relatively extreme situation, because it means that even without computing the tax revenues associated with all commercial relationships with the remaining Spanish ACs, this community can still manage a closer budget amount on its own than it could obtain with the current financial system. It is also worth noting that, without the poor regions formed by $S$, the other Spanish regions $N \backslash S$ obtain an even greater excess equal to $€-74$ million $<0$ (although still negative).

Let us consider again the Spanish allocation $S p$, and compare it with what we obtain by applying the balanced allocation $\varphi$ and with the weighted balanced allocation $\varphi^{w}$. We show the data in the following Table 4 (for a better visualisation of the redistributive effects of these rules, we have placed the CAs in decreasing order according to

Table 4 Comparison of the Spanish rule with the balanced allocation and the weighted balanced allocation

\begin{tabular}{|c|c|c|c|c|c|c|c|c|}
\hline Acs & $\begin{array}{l}\text { Adjusted } \\
\text { revenues }\end{array}$ & $S p$ & $(\varphi)$ & $\left(\varphi^{w}\right)$ & $\mathrm{IGDP}^{\mathrm{h}}$ & $\mathrm{SpGDP}^{\mathrm{h}}$ & $\mathrm{jGDP}^{\mathrm{h}}$ & $\mathrm{j}^{\mathrm{w}} \mathrm{GDP}^{\mathrm{h}}$ \\
\hline $\mathrm{Ma}$ & $73,142.3$ & $53,937.6$ & 64,938 & 58,179 & 33,314 & 30,334 & 32,041 & 30,992 \\
\hline $\mathrm{Na}$ & 6230.1 & 6345.0 & 6667 & 6478 & 27,680 & 27,860 & 28,363 & 28,068 \\
\hline PV & $22,755.8$ & $26,143.3$ & 23,930 & 23,208 & 27,670 & 29,217 & 28,206 & 27,876 \\
\hline Cat & $76,222.5$ & $66,330.2$ & 75,330 & 73,531 & 27,520 & 26,203 & 27,401 & 27,161 \\
\hline $\mathrm{Ba}$ & $10,459.4$ & $8,943.5$ & 11,057 & 10,965 & 25,182 & 23,809 & 25,723 & 25,640 \\
\hline Ara & $12,372.0$ & $13,215.9$ & 14,432 & 14,586 & 24,152 & 24,791 & 25,711 & 25,828 \\
\hline $\mathrm{Ri}$ & 2868.6 & 2910.4 & 3024 & 3037 & 23,897 & 24,029 & 24,385 & 24,425 \\
\hline $\mathrm{Va}$ & $40,040.6$ & $38,306.0$ & 41,681 & 42,713 & 19,841 & 19,493 & 20,169 & 20,376 \\
\hline Cnt & 5281.2 & 5796.8 & 5442 & 5654 & 19,476 & 20,354 & 19,750 & 20,112 \\
\hline C-L & $21,074.8$ & $25,354.9$ & 22,444 & 23,286 & 19,186 & 20,910 & 19,738 & 20,077 \\
\hline $\mathrm{Ga}$ & $22,382.9$ & $26,074.7$ & 22,502 & 23,159 & 18,324 & 19,671 & 18,367 & 18,607 \\
\hline $\mathrm{Mu}$ & $10,917.0$ & $11,024.7$ & 11,797 & 12,083 & 18,045 & 18,119 & 18,645 & 18,840 \\
\hline Ast & 9472.6 & $11,571.1$ & 9,579 & 10,027 & 17,491 & 19,477 & 17,592 & 18,015 \\
\hline Cana & $13,878.1$ & $18,171.6$ & 14,595 & 15,345 & 16,873 & 18,915 & 17,214 & 17,571 \\
\hline C-M & $15,395.1$ & $17,028.8$ & 16,662 & 18,255 & 16,479 & 17,269 & 17,091 & 17,861 \\
\hline An & $60,235.3$ & $67,924.6$ & 58,247 & 60,903 & 15,600 & 16,516 & 15,364 & 15,680 \\
\hline Ex & 7520.3 & $10,347.0$ & 7804 & 8570 & 12,623 & 15,201 & 12,882 & 13,580 \\
\hline CyMel & 1061.9 & 1884.8 & 1180 & 1330 & 12,543 & 17,393 & 13,238 & 14,125 \\
\hline
\end{tabular}


their $I G D P^{h}$ and decreasing values with respect the Adjusted revenues have been highlighted in italics).

We have italicised and shaded values that are worse than adjusted revenues $A T$, for each of the budget allocations $S p, \varphi$, and $\varphi^{w}$.

Now, in order to compare the stability of the three allocations, we compute the threshold regional values for each one. Next, we show them in Table 5. We add the additional column $R G D P^{h}$ to normalise the $I G D P^{h}$ values between 0 and 1 . That is,

$$
R G D P_{i}^{h}=\frac{I G D P_{i}^{h}-\min _{j \in N} I G D P_{j}^{h}}{\max _{j \in N} I G D P_{j}^{h}-\min _{j \in N} I G D P_{j}^{h}}
$$

In this way, we show the results homogeneously. We can thus observe the budget allocation evolution over time, or compare their stability between different countries, if desired. Given the threshold values obtained, we can rank the regions in decreasing order. Those at the top have a lower value of $\alpha$ and thus are the ones that will have more reasons for complaint.

Consider again the Basque Country $(P V)$ and Catalonia ( $C a t)$, with high secessionist aspirations. The threshold value for the Basque Country is $\alpha_{P V}(S p)=1.551>1$. It is then in a better position with the present system $(S p)$ than it would be if it were an independent fiscal entity $\left(\zeta^{1}\right)$. Although the Balearic Islands $(B a)$ have a negative excess, $e\left(\{B a\}, S p, v_{t}\right)=€-461$ million $<0$, they have a very low threshold value

Table 5 Spanish regions ordered by their threshold values with respect to $\boldsymbol{S p}, \boldsymbol{\varphi}$, and $\varphi^{\boldsymbol{w}}$

\begin{tabular}{|c|c|c|c|c|c|c|c|c|}
\hline & $I G D P^{h}$ & $R I G D P^{h}$ & & $\alpha(S p)$ & & $\alpha(\varphi)$ & & $\alpha\left(\varphi^{w}\right)$ \\
\hline $\mathrm{Ma}$ & 33,314 & 1.00 & $B a$ & 0.233 & $M a$ & 0.761 & $M a$ & 0.565 \\
\hline $\mathrm{Na}$ & 27,680 & 0.73 & $M a$ & 0.441 & $A n$ & 0.895 & Cat & 0.860 \\
\hline PV & 27,670 & 0.73 & Cat & 0.487 & Cat & 0.954 & An & 1.035 \\
\hline Cat & 27,520 & 0.72 & $V a$ & 0.862 & $\mathrm{Ga}$ & 1.019 & PV & 1.074 \\
\hline $\mathrm{Ba}$ & 25,182 & 0.61 & $\mathrm{Mu}$ & 1.027 & Ast & 1.029 & $\mathrm{Na}$ & 1.102 \\
\hline Ara & 24,152 & 0.56 & $\mathrm{Ri}$ & 1.030 & Cnt & 1.072 & $\mathrm{Ri}$ & 1.120 \\
\hline $\mathrm{Ri}$ & 23,897 & 0.55 & $\mathrm{Na}$ & 1.047 & Ex & 1.091 & $\mathrm{Ga}$ & 1.127 \\
\hline $\mathrm{Va}$ & 19,841 & 0.35 & Ara & 1.160 & $\mathrm{Ri}$ & 1.111 & Ast & 1.149 \\
\hline $\mathrm{Cnt}$ & 19,476 & 0.33 & C-M & 1.208 & $\mathrm{Va}$ & 1.131 & $\mathrm{Cnt}$ & 1.167 \\
\hline C-L & 19,186 & 0.32 & Cnt & 1.230 & C-M & 1.162 & $\mathrm{Va}$ & 1.213 \\
\hline $\mathrm{Ga}$ & 18,324 & 0.28 & An & 1.408 & CyMel & 1.165 & $\mathrm{Ba}$ & 1.256 \\
\hline $\mathrm{Mu}$ & 18,045 & 0.26 & C-L & 1.550 & Cana & 1.167 & C-L & 1.284 \\
\hline Ast & 17,491 & 0.24 & PV & 1.551 & C-L & 1.176 & $\mathrm{Mu}$ & 1.290 \\
\hline Cana & 16,873 & 0.21 & Ast & 1.564 & $\mathrm{Na}$ & 1.180 & Ex & 1.337 \\
\hline C-M & 16,479 & 0.19 & $\mathrm{Ga}$ & 1.603 & PV & 1.191 & Cana & 1.341 \\
\hline An & 15,600 & 0.15 & Ex & 1.907 & $\mathrm{Mu}$ & 1.219 & C-M & 1.365 \\
\hline Ex & 12,623 & 0.00 & Cana & 1.998 & $\mathrm{Ba}$ & 1.302 & CyMel & 1.376 \\
\hline CyMel & 12,543 & 0.00 & CyMel & 2.153 & Ara & 1.390 & Ara & 1.419 \\
\hline
\end{tabular}




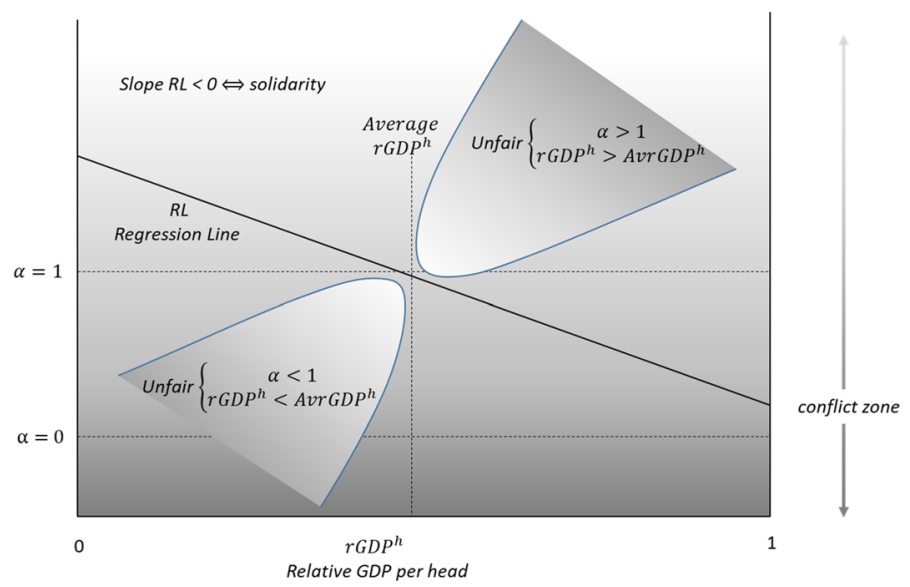

Fig. 5 Hotspots for different $\alpha$ values

$\alpha_{B a}(S p)=0.223$. Let $S$ the coalition given by four of the latter in the ranking of $G D P$ per capita, $S=\{C y M e l, A n, E x, C a n a\}$, being $N \backslash S$ the set formed by the rest of Spanish regions. The excess of $N \backslash S$ is $e\left(N \backslash S, S p, v_{t}\right)=€-74$ million $<0$. Their threshold value is $\alpha_{N \backslash S}(S p)=0.142$ which is also very low.

We can also show the regression line of these values in a graph. Typically, it should be as shown in Fig. 5.

The negative slope of the linear regression clearly indicates a redistributive effect of wealth. The rule treats regions better the poorer they are. The lower shaded part of the graph shows the conflict zone from the point of view of stability (with $\alpha_{i}(\psi)$ close to 0$)$. It is also problematic that many regions are placed in unfair areas. Being in the northeast part of the graph means having a wealth per capita that is higher than the average and, at the same time, benefiting from a greater budget expenditure than if an amount equivalent to the total amount collected in the region were spent $\left(\alpha_{i}(\psi)>1\right)$. The regions located in the southwestern area are clearly discriminated by $\psi$, since they have a lower than average per capita wealth and, at the same time, have a positive fiscal balance, which implies a net transfer of fiscal resources to the other regions. ${ }^{32}$

Figure 6 provides an overview of the stability pattern of Spanish allocation $S p$.

Again, this shows the worrying cases of $P V$ and $N a$ with per capita wealth at the top of the ranking, and with threshold values above one, and with the case of $V a$ with a threshold value lower than one, and a per capita wealth lower than the average.

We could consider the number of ACs with threshold values $\alpha(S p)<1$ excessive. They are $\{B a, M a, C a t, V a\}$. They include: Catalonia, with high secessionist support; the Balearics, with a well-founded grievance against the present Spanish allocation; and Valencia, whose $I G D P^{h}$ is lower than average, has a positive adjusted fiscal balance, and ends, after the application of the $S p$ allocation, with a final $S p G D P^{h}$ even worse than initially. Indeed, the coalition $C C=\{C a t, B a, V a\}$ of so-called Catalan Countries has a threshold value of $\alpha_{C C}(S p)=0.476<1$. If the present Spanish

$\overline{32 \alpha_{i}(\psi)<1 \text { is equivalent to } \psi_{i}}<T_{i}$. 


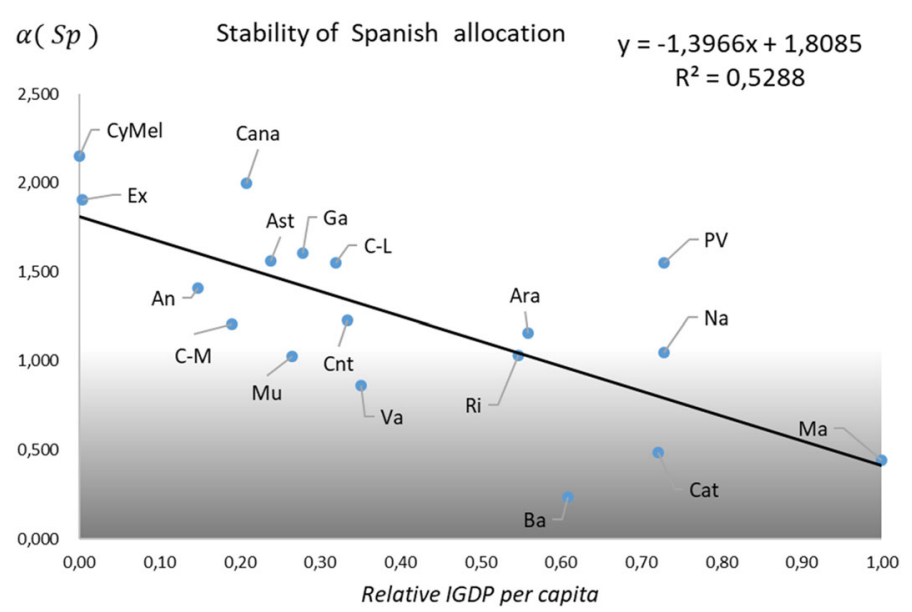

Fig. 6 Stability of Spanish rule

Table 6 Threshold value evolution of the rest of Spain with respect to the foral communities

\begin{tabular}{lllll}
\hline Year & 2011 & 2012 & 2013 & 2014 \\
\hline$\alpha_{N \backslash F}(S p)$ & 0.8684459 & 0.8373311 & 0.813369 & 0.6664546 \\
\hline
\end{tabular}

financial system does not change, the nationalist concept of "Catalan Countries" could gain force in the future.

The case of "Foral Communities" coalition, $F=\{N a, P V\}$, formed by the Basque Country $(P V)$ and Navarre $(\mathrm{Na})$, is also interesting. Both communities have an $I G D P^{h}$ above average and are currently among the richer regions in Spain. After the application of the $S p$ allocation, they end up with a final $S p I G D P^{h}$ even better than initially. Such a situation would be considered a privilege with respect to the remaining regions that follow the common financial system. There has been a tendency for such discriminatory positions to increase in recent years. Correspondingly, the threshold value for the rest of Spain without foral communities, i.e. $N \backslash F$, decreases, as can be seen in next Table 6 .

It is desirable to find an agreement on a new regional financial system in Spain, improving its stability by minimising the reasonable grievances that ACs can hold. Otherwise, the current regional financial system will be a source of increasing political instability.

Following Fig. 7 shows the values for the balance allocation $\varphi$ and the weighted balanced allocation $\varphi^{w}$.

From the point of view of stability, the behaviour of $\varphi$ improves, as few regions are in the conflict zone, $\alpha(\varphi)<1$, only $\{\mathrm{Ma}, \mathrm{Cat}, \mathrm{An}\}$. Conversely, the slope of the regression line is almost zero, indicating a poor redistribution of wealth. 

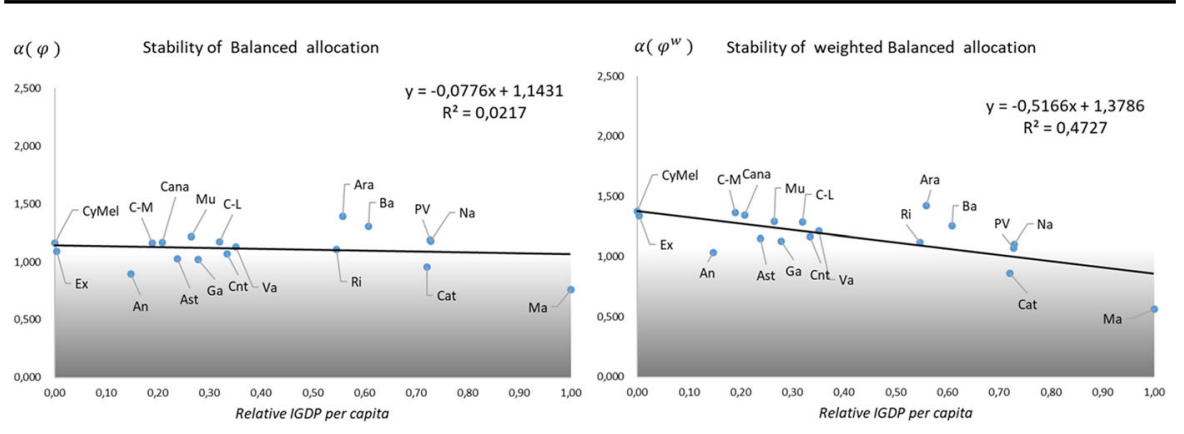

Fig. 7 Stability comparison of the rules $\varphi$ and $\varphi^{w}$

For the case of $\varphi^{w}$, only two ACs are in the conflict zone, $\{M a, C a t\}$, and the slope of the regression line is more negative, corresponding to a greater degree of wealth distribution.

There is an additional issue related to the redistribution of wealth, which is the ordinality principle: the redistributive effect of a rule "should narrow financing disparities across regions without altering their needs-adjusted relative ranking." 33

In other words, it cannot be that a region $i$ with initial $I G D P_{i}^{h}$ greater than of region $j ; i$ transfers wealth to $j$, and after that, $i$ ends with a final $\psi G D P_{i}^{h}$ lower than region $j$. We can therefore say that a budget allocation $\psi$ satisfies ordinality if its application preserves the ranking of the regions by their wealth per capita:

$$
I G D P_{i}^{h}<I G D P_{j}^{h} \Leftrightarrow \psi G D P_{i}^{h}<\psi G D P_{j}^{h}
$$

As shown in Sect. 3, the Spanish allocation $S p$ breaks clearly such a principle: 12 pairs of ACs interchange their position ranking. The balanced allocation $\varphi$ works much better, and only two pairs change their position: $\{(G a, M u),(C y M e l, E x)\}$. The weighted balanced allocation $\varphi^{w}$ works a litthe worse in this sense, as four pairs of regions change their position: $\{($ Ara,$B a),(M u, G a),(C-M, C a n a),(C y M e l, E x)\}$.

We can observe an indirect relationship between the principles of solidarity (wealth redistribution) and ordinality. Given the unequal wealth distribution in Spain, the most solidary budget allocation considered here, the Spanish allocation $S p$, turns out to be relatively unstable. Furthermore, it exhibits bad behaviour from the ordinality point of view. In the opposite direction, the balanced allocation $\varphi$ works better from the stability and ordinality side, although at the cost of being supportive. The weighted balanced allocation $\varphi^{w}$ is a trade-off between these two opposite sides: stability and ordinality on one hand, and solidarity/redistribution on the other.

33 De la Fuente et al. (2016). 


\section{Conclusions and final remarks}

The purpose of this exercise is twofold: theoretical and applied. From a theoretical perspective, we wish to show the stability analysis of the budget regional distribution that can be carried out with the help of the tax game. We believe it to be particularly relevant in the debate regarding regional fiscal balances. The Spanish case has been used to apply this analysis.

We have presented two different concepts of stability. In one concept, the fiscal sovereignty over all resources collected in a region belongs exclusively to its regional authorities. In this case, we use the fiscal balances as benchmarks to measure the degree of satisfaction or disagreement with the total budgetary expenditure obtained by the region. There is little room for negotiation here. Significant differences between the collected and the obtained will always be viewed with suspicion. The consequence of this approach is that the only stable budget allocation involves spending in each region the equivalent of what is collected in it.

In the other concept we share the fiscal sovereignty among all the regions that make up the country. We cannot consider regions as economic autarchies. We should consider a good part of the fiscal resources collected in each region as common property, given that they originate from the exchange of goods and services between economic agents residing in the different regions that form the country. According to this approach, at least that shared part of fiscal resources can be the subject of negotiation in its redistribution, widening the scope for negotiation.

We have used the $v_{t}^{\alpha}$ tax game to estimate those resources that can be the object of negotiation. We approach the first concept of stability by $v_{t}^{1}$, while in the second we use the core of the game $v_{t}^{0}$. Apparently, the two approaches are incompatible; however, parameter $\alpha$ allows us to pass from one to the other smoothly. In this way, we can take a more nuanced view, and not see exclusively in black or white terms.

In fact, the fiscal balances for Spain for the year 2014 present a certainly conflicting distribution. Although somewhat arbitrarily, the fiscal balances imply an acceptable degree of territorial solidarity. Unfortunately, Spain presents large differences in the territorial distribution of wealth, and the moderate degree of solidarity that the Spanish allocation $S p$ presents, causes its corresponding stability problems.

We have followed the theoretical exercise of applying in this context two solutions brought from the literature of cooperative games: The balanced allocation $\varphi$, which coincides with the nucleolus and the Shapley value of the game $v_{t}^{0}$, and the weighted balanced allocation $\varphi^{w}$, which coincides with the weighted Shapley value of $v_{t}^{0} \cdot \varphi$ is the most stable and best behaved in preserving regional rankings of wealth per capita, but, in comparison, it redistributes little wealth between rich and poor regions. $\varphi^{w}$ is less stable and slightly worse in preserving rankings than $\varphi$, but it behaves better by redistributing wealth. We can therefore consider $\varphi^{w}$ as an acceptable compromise between the principles of solidarity, stability and ordinality.

The analysis of fiscal balances using the tax game tool relates only to the ratio between the total expenditures made by all public administrations in the territory and the total revenues obtained. We can use it to decide how much should be spent on each territory, irrespective of how to distribute this amount among the different public authorities. Once we decide how much to allocate to each region, how to distribute the 
different expenditure items between the central government and the corresponding regional and local authorities becomes a different, though not trivial, problem. We should address both issues separately, and they ought not be intertwined.

One aspect related to the process of agreeing on a budget allocation among the regions is the trust between them regarding the data provided on taxes collected. Depending on the tax rule selected, it opens the door to a possible strategic manipulation of the data. There are many papers devoted to designing rules that are immune to such manipulation. This non-manipulability condition is called strategy-proofnees (see the classical papers of Gibbard (1973) and Satterwhite (1975)). An example of application to a claims/taxation problem is Ju et al. (2007), where agents can merge/split their claims; and an application to fiscal competition among jurisdictions is Wildasin (1988). We can make two comments here. First, a way to overcome this problem is to create a common and independent fiscal authority in charge of collecting all taxes, which provide the tax vectors $I$ and $R$; and a common and independent research centre in charge to collect and provide all data related to the matrix $\boldsymbol{C}$. Obviously, the decision about how to distribute and how to spend the budget is a political decision for the political authorities. Second, there is an indirect way to deduce the plausibility of the data provided by a region. Suppose that each region $i$ announces as data the values of $T_{i}=I_{i}+R_{i}$, and their corresponding values of matrix $C$, that is, $\left(c_{i 1}, \ldots, c_{i n}\right)$, $\left(c_{1 i}, \ldots, c_{n i}\right), x_{i}$ and $m_{i}$, from which announces the coefficients $I_{i j}$ and $R_{i j}$. If a region $i$ intends to underestimate its values to benefit from this misrepresentation, the data provided must be compatible with that provided by the others. For example, $c_{i j}$ and $c_{j i}$ announced by $i$ should be equal to that of coefficients announced by $j$. Otherwise, someone is cheating.

We end by mentioning some issues that would be of interest for further research.

From a theoretical point of view:

1. Converting the problem of redistributing the public budget between regions into the problem about deciding which solution to select in a cooperative tax game, opens a new line of exploration. There are many works that analyse the cooperative solution rules axiomatically. Many of the properties considered in this literature could be transferred to our context, allowing a better evaluation and comparison of different tax financing rules.

2. There is a computational problem in checking whether a budget allocation belongs to the core of the tax game $\left(N, v_{t}^{0}\right)$. The size of the subcoalitions of $N$ is $2^{n}$ and increases exponentially with $n$. It would be of interest to find efficient algorithms to check whether an allocation belongs to the core in polynomial time, helping with the convexity and simplicity of $v_{t}^{\alpha}$.

3. It would be of interest to apply other cooperative solution concepts to the tax games setting, such as the Dutta-Ray egalitarian solution (see Dutta and Ray 1989).

From a practical perspective:

4. We can extend this stability analysis of the financial regional system to any country, or confederation of countries, such as the EU, USA, whenever data for taxes and inter-regional commercial trade are available.

5. To the extent that a practical application is sought, there is ample room for improvement in the data collected. There is a great deal of hidden work in constructing 
fiscal balances, extracting data from the National Accounts, etc. The data presented here for the Spanish case are taken from public entities, and without subsequent manipulation, however, the more plausible the fiscal balance data are, the more plausible the tax game will be.

Acknowledgements The author would like to thank the co-editor Juan D. Moreno-Ternero and two anonymous referees for their helpful comments and suggestions. Financial support from the Spanish Ministerio de Economía, Industria y Competitividad [Grant Number ECO2016-75575-R founded by MCIN/AEI/10.13039/501100011033]; the Spanish Ministerio de Ciencia, Innovación y Universidades [Grant Number PID2019-110790RB-100 founded by MCIN/AEI/10.13039/501100011033]; and from the Generalitat Valenciana under the Prometeo Excellence Program [Grant Number 2019/095] is gratefully acknowledged.

\section{Declarations}

Conflict of interest The author declares that he has no conflict of interest.

Ethical approval This article does not contain any studies with human participants or animals performed by the author.

Informed consent The author of this paper agrees with the submission of the paper to the Journal of the Spanish Economic Association (SERIEs). The author declares no ethical issues or issues needing informed consent.

Open Access This article is licensed under a Creative Commons Attribution 4.0 International License, which permits use, sharing, adaptation, distribution and reproduction in any medium or format, as long as you give appropriate credit to the original author(s) and the source, provide a link to the Creative Commons licence, and indicate if changes were made. The images or other third party material in this article are included in the article's Creative Commons licence, unless indicated otherwise in a credit line to the material. If material is not included in the article's Creative Commons licence and your intended use is not permitted by statutory regulation or exceeds the permitted use, you will need to obtain permission directly from the copyright holder. To view a copy of this licence, visit http://creativecommons.org/licenses/ by/4.0/.

\section{Appendix}

\section{Proof of Theorems}

Tax games $v_{t}^{\alpha}$ considered in Sect. 4 are convex games. Since convexity guarantees the existence of a non-empty core (Shapley 1971; Ichiishi 1981), we first prove this property. We say that $(N, v)$ is a convex game if for all $S, T \subseteq N$ it holds that $v(S)+v(T) \leq v(S \cup T)-v(S \cap T)$. An equivalent condition for convexity is

$$
m_{i}(S, v)=v(S \cup i)-v(S) \leq m_{i}(T, v)=v(T \cup i)-v(T)
$$

for all $i \in N$ and $S \subset T \subset N \backslash i, S \neq T$.

Theorem 6 For every tax problem $(N, \boldsymbol{R}, \boldsymbol{I}) \in \mathcal{T}^{N}$, the tax game $\left(N, v_{t}^{\alpha}\right)$ is convex for all $0 \leq \alpha \leq 1$

Proof It is easy to check that $v_{t}^{\alpha}(S \cup i)-v_{t}^{\alpha}(S)=t_{i i}+\alpha \sum_{j \in S}\left(R_{i j}+I_{j i}\right)$ for all $S \subset N \backslash i$. 
Thus, it is satisfied that $m_{i}\left(T, v_{t}\right)-m_{i}\left(S, v_{t}\right)=\alpha \sum_{j \in T \backslash S}\left(R_{i j}+I_{j i}\right) \geq 0$, and then $\left(N, v_{t}^{\alpha}\right)$ is convex.

Note that the existence part of Theorems 1 and 4 is corollaries of Theorem 6. To complete the proofs, it only remains to prove the following proposition.

Proposition 1 For every tax problem $(N, \boldsymbol{R}, \boldsymbol{I}) \in \mathcal{T}^{N}, T \in C\left(N, v_{t}^{\alpha}\right) \neq \varnothing$.

Proof Take the budget allocation $T$ and $0 \leq \alpha \leq 1$. Then, for any coalition $S$ it holds

$$
e_{\alpha}(S)=v_{t}^{\alpha}(S)-\sum_{i \in S} T_{i}=(\alpha-1) \sum_{i \in S} \sum_{j \in N \backslash S}\left(R_{i j}+I_{j i}\right) \leq 0 .
$$

Hence, $T \in C\left(N, v_{t}^{\alpha}\right)$.

We briefly recall the definitions of the Shapley value and the nucleolus.

Let $(N, v)$ be a game, and let $\pi: N \rightarrow N$ be a permutation of the player set $N$. Denote by $\Pi(N)$ the set of all permutations defined in $N$. We interpret $\pi$ as an order defined between players in $N$, i.e. each player $i$ enters in position $\pi(i)$ in the order $\pi$. Denote by $P_{\pi}(i)$ the set of predecessors of $i$ in order $\pi$, that is $P_{\pi}(i):=$ $\{j \in N: \pi(j)<\pi(i)\}$. The marginal contribution that each player $i \in N$ receives in every order $\pi \in \Pi(N)$ is given by $m_{i}^{\pi}(N, v)=m_{i}\left(P_{\pi}(i), v\right)=v\left(P_{\pi}(i) \cup i\right)-$ $v\left(P_{\pi}(i)\right)$. The marginal vector $m^{\pi}(N, v) \in \mathbb{R}^{N}$ of the game $(N, v)$ is defined by $m_{i}^{\pi}(N, v):=m_{i}\left(P_{\pi}(i), v\right)$, for all $i \in N$, and $\pi \in \Pi(N)$. It is immediate that $\sum_{i \in N} m_{i}^{\pi}(N, v)=v(N)$.

The Shapley value (Shapley 1953a, b) of the game is defined as:

$$
S h_{i}(N, v)=\frac{1}{n !} \sum_{\pi \in \Pi(N)} m_{i}^{\pi}(N, v), \forall i \in N
$$

The value $S h_{i}(N, v)$ is the expected marginal contribution of player $i$ with respect to the uniform distribution over all orders on $N$.

Given an allocation $x$, denote by $\theta(x)$ the excess vector with respect to $x$. $\theta(x) \in \mathbb{R}^{2^{n}-1}$ is the vector that contains the excesses of all coalitions in (weakly) decreasing order. Let $\theta(x), \theta(y) \in \mathbb{R}^{2^{n}-1}$ be two excess vectors. We say that $\theta(x)$ is lexicographically smaller than $(y), \theta(x) \leq{ }_{L} \theta(y)$, if either $\theta(x)=\theta(y)$, or there is $i \in\left\{1,2, \ldots, 2^{n}-1\right\}$ such that $\theta_{j}(x)=\theta_{j}(y)$, for each $j<i$, and $\theta_{i}(x)<\theta_{i}(y)$. We define the imputation set of a game $(N, v)$ by the set of all efficient and individually rational allocations. That is,

$$
I(N, v)=\left\{x \in \mathbb{R}^{N}: x(N)=v(N) \wedge x_{i} \geq v(i), \forall i \in N\right\}
$$

The nucleolus of a game, $\eta(N, v)$, is the set

$$
\eta(N, v)=\left\{x \in I(N, v): \theta(x) \leq{ }_{L} \theta(y), \forall y \in I(N, v)\right\}
$$


When $I(N, v) \neq \varnothing$, the nucleolus selects a unique point in the imputation set. Moreover, the nucleolus is always in the core when the core is non-empty.

Before proving Theorem 2, we need two previous definitions. Given a vector $a \in$ $\mathbb{R}^{N}$, a parameter $k \in(0, \infty)$, and a game $(N, v)$, the game $(N, k v+a)$ is defined by $(k v+a)(S)=k v(S)+\sum_{i \in S} a_{i}$. We say that a solution $\psi$ satisfies covariance, if $\psi(N, k v+a)=k \psi(N, v)+a$. The Shapley value and the nucleolus satisfy covariance. A game $(N, v)$ is a 2-player game if $v(i)=0$, for all $i \in N, v(\{i, j\}) \geq 0$, for all $\{i, j\} \subset N$, and $v(S)=\sum_{\{i, j\} \subset S} v(\{i, j\})$ otherwise.

Theorem 2 For every tax problem $(N, \boldsymbol{R}, \boldsymbol{I}) \in \mathcal{T}^{N}$, the balanced tax rule $\varphi$ coincides with the Shapley value and the nucleolus of the tax game $\left(N, v_{t}\right)$.

Proof In the class of two-player games, characterised by $v(S)=0$ if $|S| \leq 1$, and $v(S)=\sum_{T \subseteq S,|T|=2} v(T)$ if $|S| \geq 2$, the Shapley value and the nucleolus coincide (see Brown and Housman (1988), and Kar et al. (2009) for a review of the literature on this coincidence). Moreover, $\operatorname{Sh}_{i}(N, v)=\frac{1}{2} \sum_{j \in N \backslash i} v(\{i, j\})$. We can express any tax game $v_{t}$ in the form of $v_{t}=v_{t}^{2}+t$. Where $t_{i}=t_{i i}$ for all $i \in N$ and $v_{t}^{2}$ is a 2-player game, in which $v_{t}^{2}(\{i, j\})=t_{i j}+t_{j i}$. It is immediate that $\varphi$ satisfies covariance. Therefore, $\varphi\left(N, v_{t}\right)=\varphi\left(N, v_{t}^{2}\right)+t$. By construction, it holds that $\varphi\left(N, v_{t}^{2}\right)=\operatorname{Sh}\left(N, v_{t}^{2}\right)=\eta\left(N, v_{t}^{2}\right)$. Finally, by covariance, we have that $\varphi\left(N, v_{t}^{2}+t\right)=\operatorname{Sh}\left(N, v_{t}^{2}+t\right)=\eta\left(N, v_{t}^{2}+t\right)$.

For the sake of completeness, we briefly review the literature of equivalence between the Shapley value and the nucleolus. Brown and Housman (1988) gave a sufficient condition for the coincidence of $S h=\eta$. This condition implies, in fact, that the excess of a coalition and its complementary are equal. The family of pessimistic tax games $v_{t}^{0}$ satisfies this sufficient condition. Note that $\left(N, v_{t}^{0}\right)$ can be seen as a cooperative game defined in an extended digraph. That is, given a weight function $t: N \times N \rightarrow \mathbb{R}_{+}$, the cooperative game $v_{t}^{0}$ is defined by $v_{t}^{0}(\varnothing)=0$ and

$$
v_{t}^{0}(S)=\sum_{(i, j) \in S \times S} t(i, j), \forall S \subseteq N, S \neq \varnothing .
$$

In an extended digraph, the pairs $(i, j)$ and $(j, i)$, with $i \neq j$, are considered different elements of the digraph, and pairs $(i, i)$ also belong to the digraph. The family of weighted graphs considered in Brown and Housman (1988), is the particular case of undirected graphs, where pairs $(i, j)$ and $(j, i)$, with $i \neq j$, are considered as the same element of the graph, and pairs $(i, i)$ are not allowed. Weighted graphs belong to the family of two-player games.

Kar et al. (2009) define a family of games called PS games. A game $(N, v)$ is a PS game if for all $i \in N$, there exists $c_{i} \in \mathbb{R}$ such that $v(S \cup i)-v(S)+v(N \backslash S)-$ $v(N \backslash(S \cup i))=c_{i}$ for all $S \subseteq N \backslash i$. This property says that the sum of a player's marginal contribution to any coalition $S$ and its complement $N \backslash(S \cup i)$ is a playerspecific constant. They prove that in the family of PS games, the Shapley value and the nucleolus coincide. Moreover, it holds that $S h_{i}(N, v)=\eta_{i}(N, v)=\frac{c_{i}}{2}$, for all $i \in N$. Any two-player game is a PS game, but not vice versa. A pessimistic tax game 
is not a two-player game, because $v_{t}^{0}(i)=t_{i i} \neq 0$; however, it is a PS game, as it is easy to check that

$$
v_{t}^{0}(S \cup i)-v_{t}^{0}(S)+v_{t}^{0}(N \backslash S)-v_{t}^{0}(N \backslash(S \cup i))=2 t_{i i}+\sum_{j \in N \backslash i}\left(t_{i j}+t_{j i}\right)
$$

for all $S \subseteq N \backslash i$.

Theorem 3 For every tax problem $(N, \boldsymbol{R}, \boldsymbol{I}) \in \mathcal{T}^{N}$, the weighted balanced allocation $\varphi^{w}$ coincides with the weighted Shapley value of the tax game $\left(N, v_{t}\right)$, i.e. $\varphi^{w}(N, \boldsymbol{R}, \boldsymbol{I})=\operatorname{Sh}^{w^{-1}}\left(N, v_{t}\right)$, where $\omega=w^{-1}$. Moreover, $\varphi^{w}(N, \boldsymbol{R}, \boldsymbol{I}) \in C\left(N, v_{t}\right)$.

Proof Hart and Mas-Colell (1989, Section 5) considered the weighted Shapley values, $S h^{\omega}$. Given a vector of weights $\omega \in \mathbb{R}_{++}^{N}$ a value $\psi$ satisfies weighted balanced contributions if

$$
\frac{1}{\omega_{i}}\left(\psi_{i}(N, v)-\psi_{i}(N \backslash j, v)\right)=\frac{1}{\omega_{j}}\left(\psi_{j}(N, v)-\psi_{j}(N \backslash i, v)\right),
$$

for every pair of players $\{i, j\} \subseteq N, i \neq j$. Hart and Mas-Colell prove that the weighted Shapley value $S h^{\omega}$ is the unique value which satisfies efficiency and weighted balanced contributions.

Now consider the tax rule $\varphi^{w}$. The vector of weights $w \in \mathbb{R}_{++}^{N}$ is given by the initial $G D P$ per capita of the region, i.e. $w_{i}=\frac{I G D P_{i}}{P_{i}}$, for all $i \in N$. Defining $\omega_{i}=w_{i}^{-1}$, it is immediately clear that if a tax rule verifies the weighted balanced contribution, for weights $\left(w_{i}\right)_{i \in N}$, in the tax problem $(N, \boldsymbol{R}, \boldsymbol{I})$ it also verifies weighted balanced contributions, for weights $\left(\omega_{i}=w_{i}^{-1}\right)_{i \in N}$, in the tax game $\left(N, v_{t}\right)$. We denote by $\boldsymbol{R}^{-j}, \boldsymbol{I}^{-j}$ the matrix where we have deleted the row and column $j$. Now, by definition, we have

$$
\varphi_{i}^{w}(N, \boldsymbol{R}, \boldsymbol{I})=t_{i i}+\sum_{j \in N \backslash i} \frac{w_{j}}{w_{i}+w_{j}} \cdot\left(t_{i j}+t_{j i}\right), \quad \forall i \in N
$$

Then it holds.

$\varphi_{i}^{w}(N, \boldsymbol{R}, \boldsymbol{I})-\varphi_{i}^{w}\left(N \backslash j, \boldsymbol{R}^{-j}, \boldsymbol{I}^{-j}\right)=\frac{w_{j}}{w_{i}+w_{j}}\left(t_{i j}+t_{j i}\right)$.

Therefore

$w_{i}\left(\varphi_{i}^{w}(N, \boldsymbol{R}, \boldsymbol{I})-\varphi_{i}^{w}\left(N \backslash j, \boldsymbol{R}^{-j}, \boldsymbol{I}^{-j}\right)\right)=w_{j}\left(\varphi_{j}^{w}(N, \boldsymbol{R}, \boldsymbol{I})-\varphi_{j}^{w}\left(N \backslash j, \boldsymbol{R}^{-i}, \boldsymbol{I}^{-i}\right)\right)$.

This implies that $\varphi^{w}$ satisfies weighted balanced contributions, with weights $\left(\omega_{i}=w_{i}^{-1}\right)_{i \in N}$. As $\varphi^{w}$ is efficient, it holds that $\varphi^{w}\left(N, v_{t}\right)=\operatorname{Sh}^{\omega}\left(N, v_{t}\right)$. We know that in convex games, $S h^{\omega}$ belongs to the core. Hence, according to Theorem 6 , $\varphi^{w}\left(N, v_{t}\right) \in C\left(N, v_{t}\right)$.

Theorem 5 For every tax problem $(N, \boldsymbol{R}, \boldsymbol{I}) \in \mathcal{T}^{N}$, the balanced tax rule is $\alpha$-stable for all $\alpha \leq 1 / 2$, i.e. $\varphi \in C\left(N, v_{t}^{\alpha}\right)$. 
Proof Let a coalition $S \subseteq N$, therefore

$$
\begin{aligned}
e\left(S, \varphi, v_{t}^{\alpha}\right)= & v_{t}^{\alpha}(S)-\varphi(N, \boldsymbol{R}, \boldsymbol{I})(S)=\sum_{i \in S} \sum_{j \in S}\left(t_{i j}+t_{j i}\right)+\alpha \sum_{i \in S} \sum_{j \in N \backslash S}\left(R_{i j}+I_{j i}\right) \\
& -\left(\sum_{i \in S} \sum_{j \in S}\left(t_{i j}+t_{j i}\right)+\frac{1}{2} \sum_{i \in S} \sum_{j \in N \backslash S}\left(t_{i j}+t_{j i}\right)\right) \\
= & \left(\alpha-\frac{1}{2}\right) \sum_{i \in S} \sum_{j \in N \backslash S}\left(R_{i j}+I_{j i}\right) .
\end{aligned}
$$

\section{Additional tables}

See Tables 7, 8 and 9. 


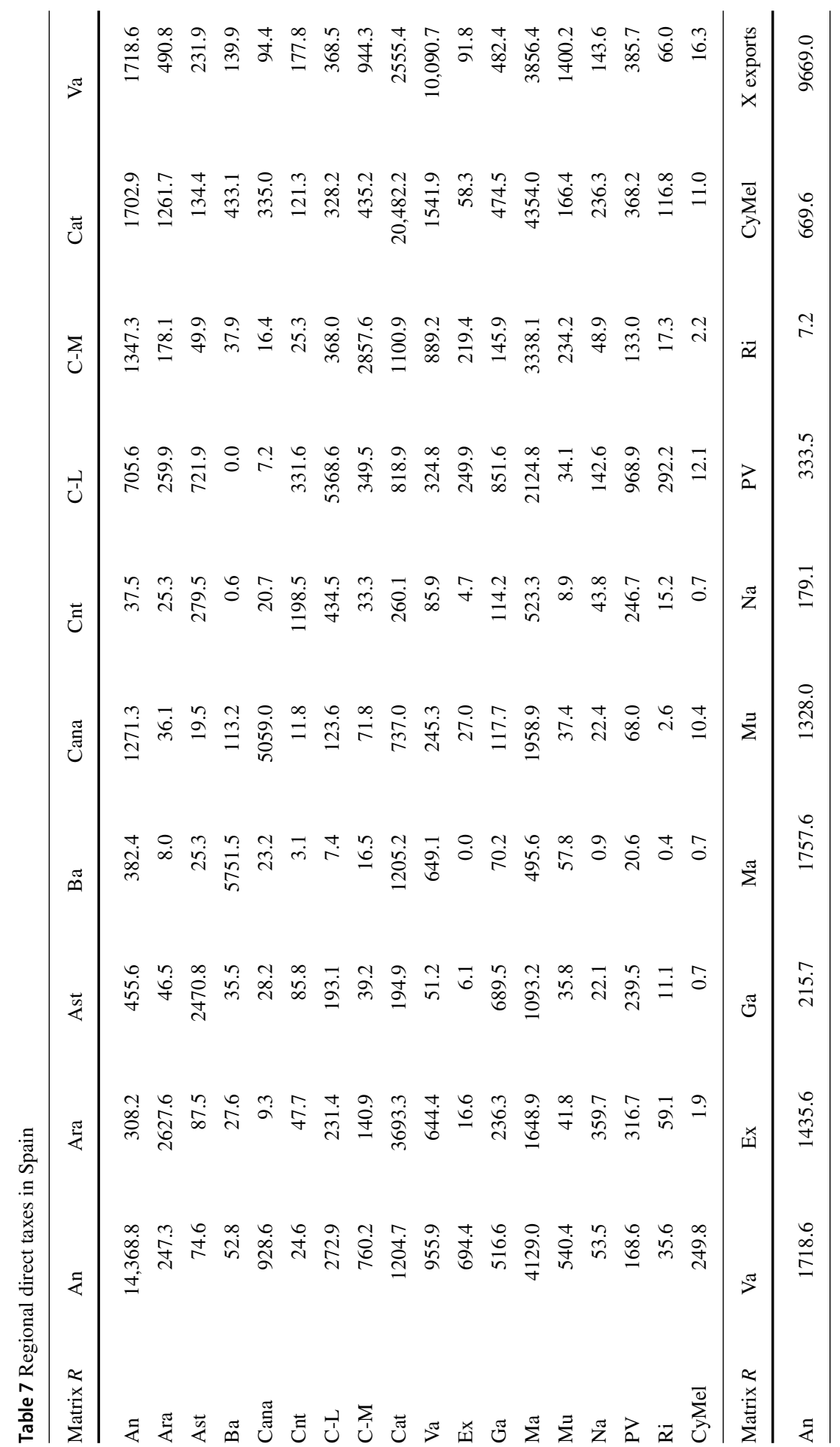




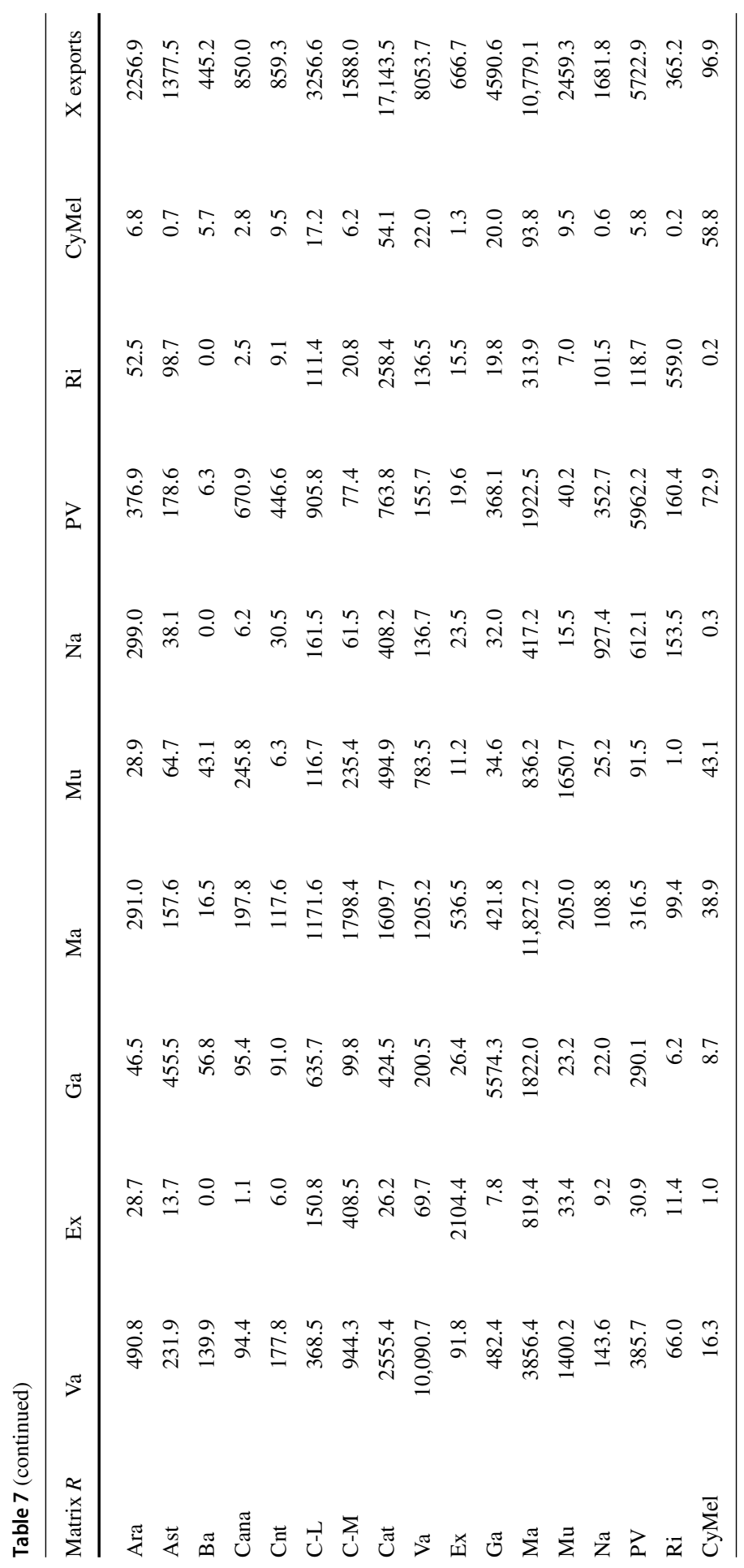




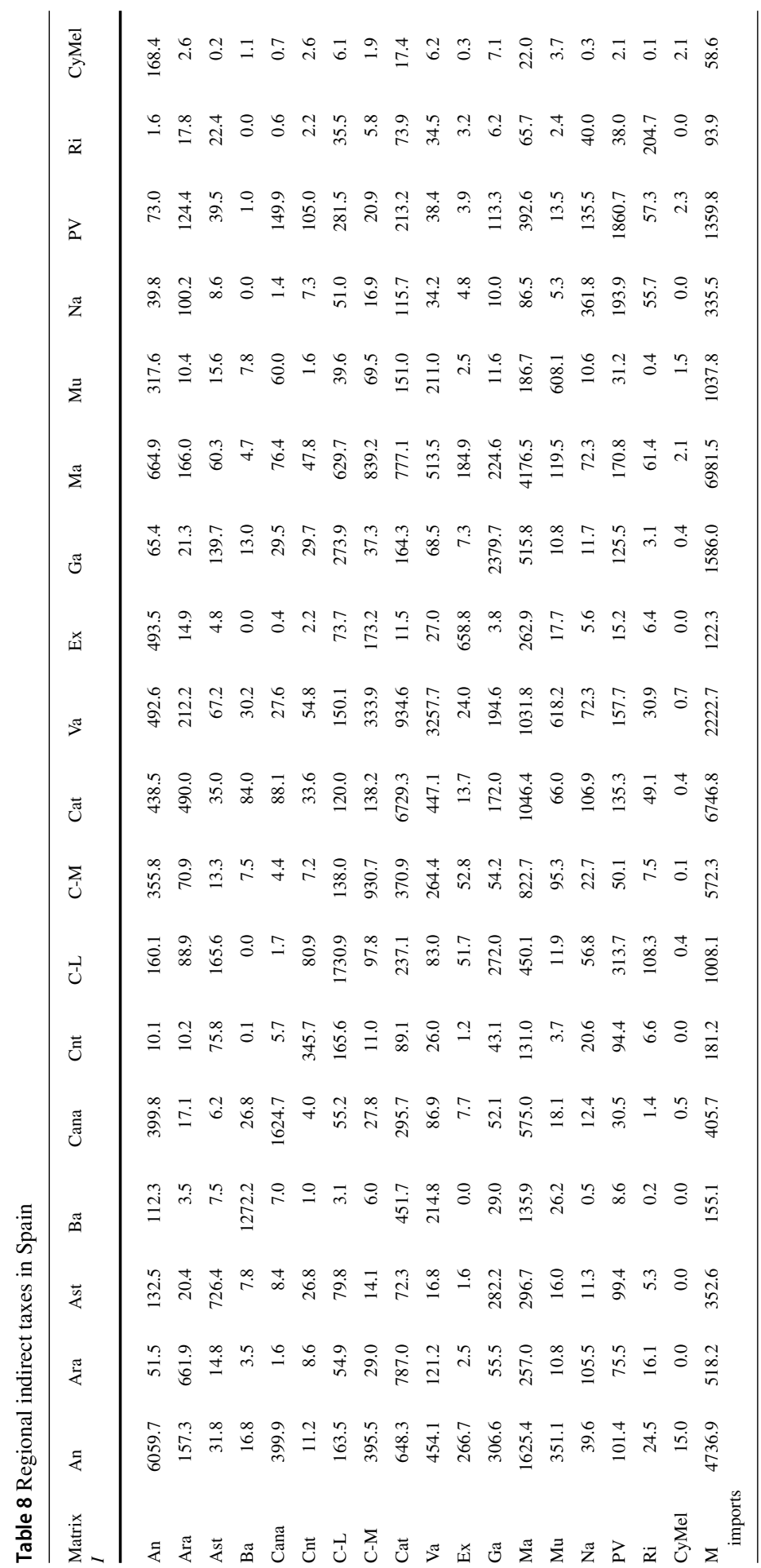




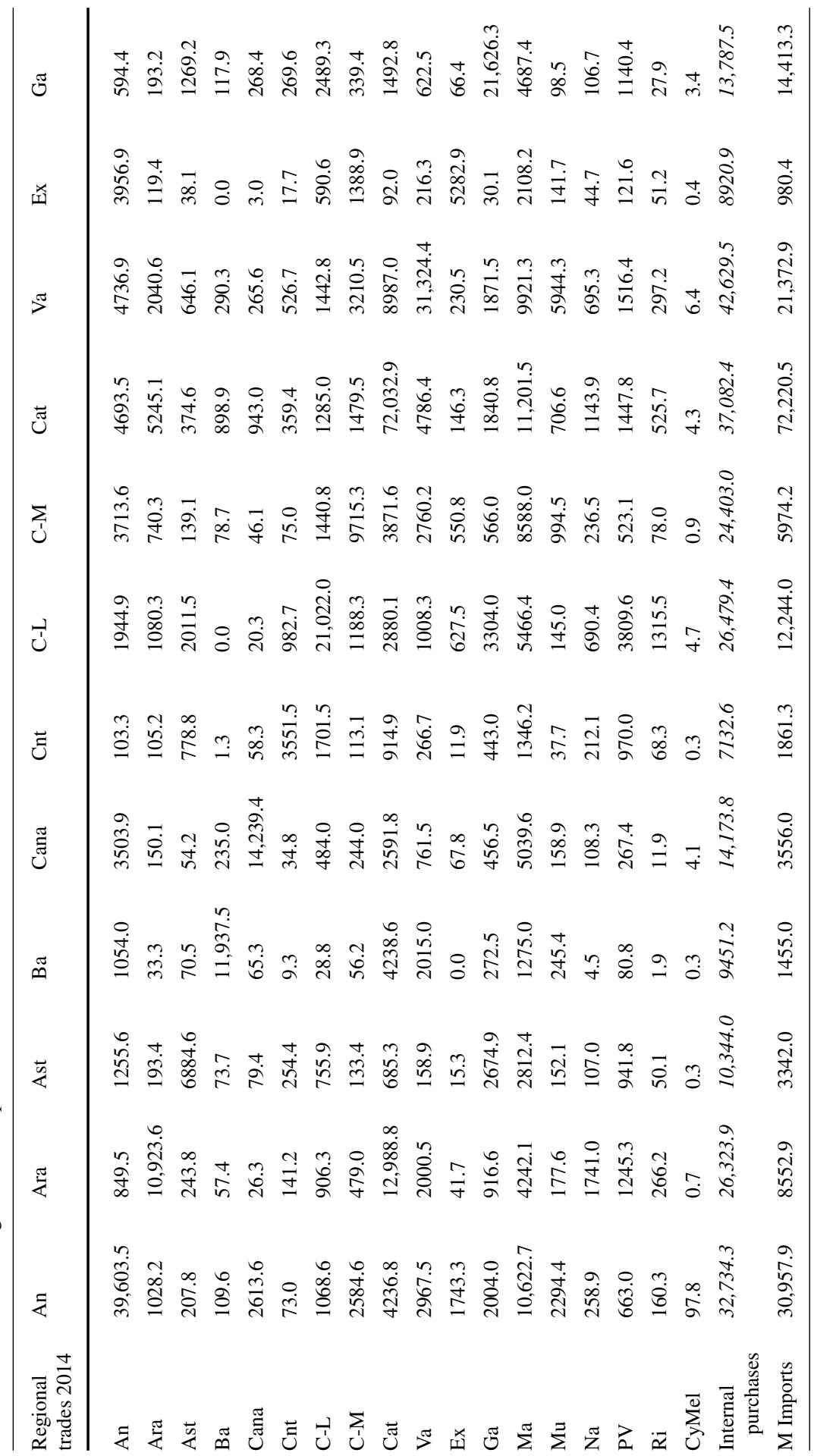




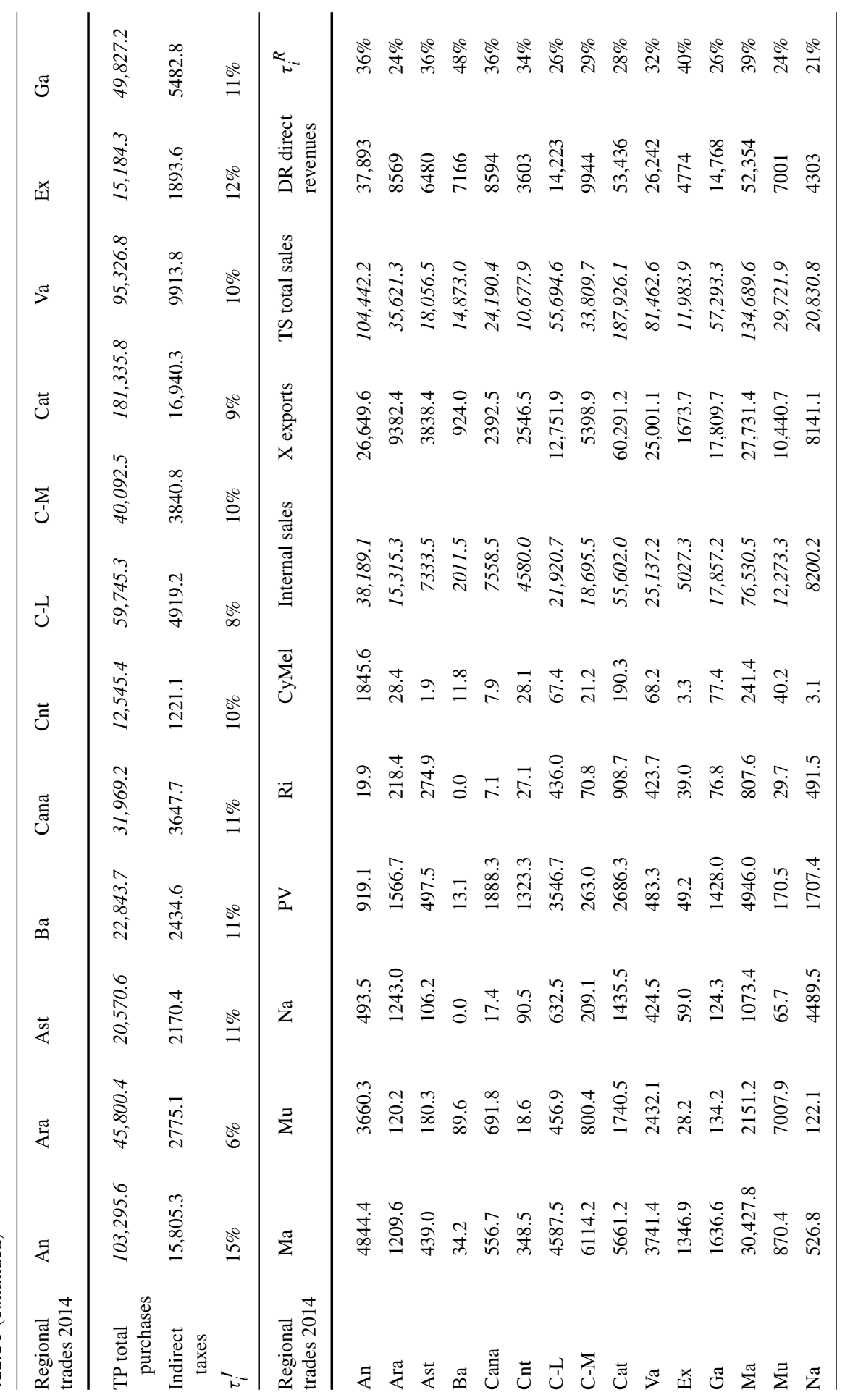




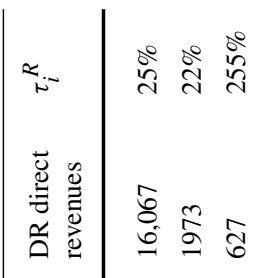

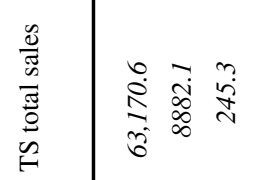

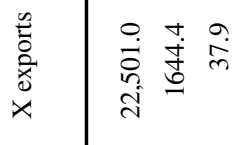

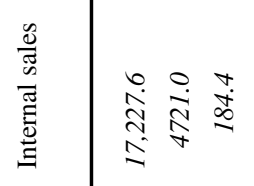

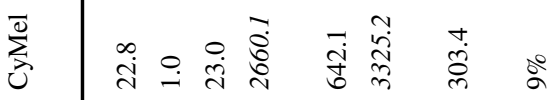

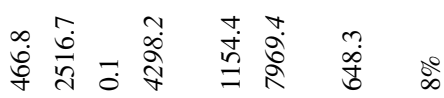

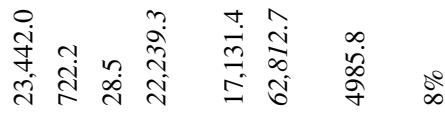

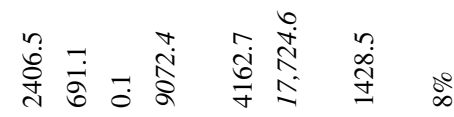

$$
\begin{aligned}
& \text { बें }
\end{aligned}
$$

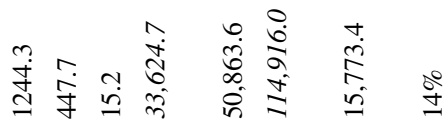

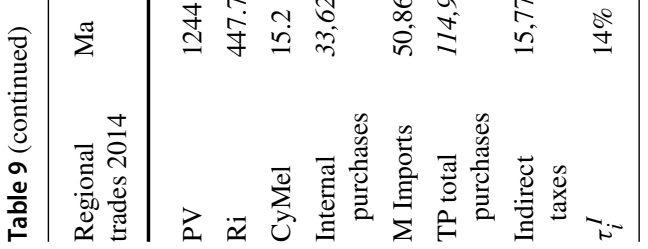




\section{References}

Aumann R, Kurz M (1977) Power and taxes. Econometrica 45(5):1137-1161

Bergantiños G, Moreno-Ternero JD (2020) Sharing the revenues from broadcasting sport events. Manag Sci 66(6):2417-2431

Brown D, Housman D (1988) Cooperative games on weighted graphs. Internal report. Worcester Polytechnic Institute, Worcester

Calvo E, García I, Zarzuelo JM (2000) Replication invariance on NTU games. Int J Game Theory 29:473-486

Calvo E, Santos JC (2000) Weighted weak semivalues. Int J Game Theory 29:1-9

Castells A, Barberán R, Bosch N, Espasa M, Rodrigo F, Ruiz-Huerta J (2000) Las balanzas fiscales de las Comunidades autónomas (1991-1996). Ariel Economía. Barcelona (in Spanish)

Davezies L, Nicot B H, Prud'homme R (1996) Economic and social cohesion in the European Union: the impact of Member States' own policies. European Commission

De la Fuente A, Barberán R, Uriel E (2014) Un sistema de cuentas públicas territorializadas para España. Metodología y resultados para 2011. Estudios sobre la Economía Española-2014/03. Fedea (in Spanish)

De la Fuente A, Thöne M, Kastrop C (2016) Regional financing in germany and spain: comparative reform perspectives. Fedea policy papers. BBVA Research No. 16/04

De la Fuente A (2014) Is Catalonia being fiscally mistreated? Barcelona GSE working paper series. WP no 766

De Sousa J, Lamotte O (2007) Does political disintegration lead to trade disintegration? Evidence from Transition Countries Econ Transit 15(4):825-843

Djankov S, Freund C (2002) Trade flows in the Soviet Union-1987 to 1996. J Comp Econ 30:76-90

Dubay C (2006) Federal tax burdens and expenditures by state. Tax Foundation, Special report no. 139, March

Dutta B, Ray D (1989) A concept of egalitarianism under participation constraints. Econometrica 57:615-635

Economics O (2008) Regional winners and losers in UK public finances. Econ Outlook 32(3):5-15

Feltkamp V (1995) Alternative axiomatic characterizations of the Shapley and Banzhaf values. Int J Game Theory 24:179-186

Ferrario C, Zanardi A (2011) Fiscal decentralization in the Italian NHS: what happens to interregional redistribution? Health Policy 100(1):71-80

Fidrmuc J, Fidrmuc J (2003) Disintegration and trade. Rev Int Econ 11:811-829

Gibbard A (1973) Manipulation of voting schemes: a general result. Econometrica 41:587-601

Gillies DB (1953) Some theorems on n-person games. Ph.D. thesis, Princeton University Press, Princeton

Giannola A, Petraglia C, Scalera D (2016) Net fiscal flows and interregional redistribution in Italy: a long-run perspective (1951-2010). Struct Change Econ Dyn 39:1-16

Hart S, Mas-Colell A (1989) Potential, value and consistency. Econometrica 57:589-614

Helliwell JF (1996) Do national borders matter for Quebec's trade? Canadian J Econ 29:507-522

Head K, Mayer T (2000) Non-Europe: the magnitude and causes of market fragmentation in the EU. Rev World Econ 136:284-314

IEB Report I (2014) IEB's report on fiscal federalism and public finance. Institut d'Economia de Barcelona (IEB)/Instituto de Estudios Fiscales (IEF)

Ichiishi T (1981) Super-modularity: applications to convex games and to the greedy algorithm for LP. J Econ Theory 25:283-286

Ju BG, Miyagawa E, Sakai T (2007) Non-manipulable división rules in claim problems and generalizations. J Econ Theory 132:1-26

Kalai E, Samet D (1987) On weighted shapley values. Int J Game Theory 16:205-222

Kar A, Mitra M, Mutuswami S (2009) On the coincidence of the prenucleolus and the Shapley value. Math Soc Sci 57:16-25

López-Casanovas G, Rosselló-Villalonga J (2014) Fiscal imbalances in asymmetric federal regimes. The Case of Spain. Hacienda Pública Española/Review of Public Economics 209-(2/2014), pp 55-97

López-Navarrete F, Sánchez-Soriano J, Bonastre OM (2019) Allocating revenues in a Smart TV ecosystem. Int T Oper Res 26(5):1611-1632

McCallum JCP (1995) National Borders Matter: Canada-US Regional Trade Patterns. Am Econ Rev $85: 615-623$ 
Magerman G, Studinka Z, Van Hove J (2016) Distance and Border Effects in International Trade: A Comparison of Estimation Methods. Economics: The Open-Access. Open-Assess E-J 10:1-31

Maschler M (1992) The bargaining set, kernel, and nucleolus. In: Aumann R, Hart S (eds) Handbook of game theory with economic applications, vol 1. North Holland, Amsterdam, pp 591-667

Maschler M, Peleg B, Shapley LS (1979) Geometric properties of the kernel, nucleolus, and related solution concepts. Math Oper Res 4(4):303-338

McLean I, McMillan A (2003) The distribution of public expenditure across the UK regions. Fisc Stud 24(1):45-71

Meinhardt HI (2012) MatTuGames. http://www.mathworks.com/matlabcentral/fileexchange/35933mattugames

Monastell G, Sánchez E (2012) Comparació internacional de les balances fiscals de les regions amb el sector públic central: una anàlisi de l'efecte redistributiu. Papers de treball. Departament dÉconomia i Coneixement. Generalitat de Cataluny (in Catalan)

Monderer D, Samet D, Shapley LS (1992) Weighted values and the core. Int J Game Theory 21:27-39

Moreno-Ternero JD, Villar A (2006) On the relative equitability of a family of taxation rules. J Public Econ Theory 8:283-291

Morgenroth E (2010) The regional dimension of taxes and public expenditure in Ireland. Reg Stud 44(6):777-789

Myerson R (1980) Conference Structures and Fair Allocation rules. Int J Game Theory 9:169-182

Office for National Statistics (2018a) Country and regional public sector finances: financial year ending 2017. https://www.ons.gov.uk/economy/governmentpublicsectorandtaxes/publicsectorfinance/ articles/countryandregionalpublicsectorfinances/2016to2017

Office for National Statistics (2018b) Country and regional public sector finances: methodology guide. https://www.ons.gov.uk/economy/governmentpublicsectorandtaxes/publicsectorfinance/ methodologies/countryandregionalpublicsectorfinancesmethodologyguide

O’Neill B (1982) A problem of rights arbitration from the Talmud. Math Soc Sci 43:1-28

Rawls J (1971) A theory of justice. Harvard University Press, Cambridge

Ruggeri GC (2010) Interregional fiscal flows: Canada. In: Bosch N, Espasa M, Solé Óllé A (eds) The political economy of inter-regional fiscals flows: measurement, determinants and effects on country stability. Edward Elgar, Barcelona, pp 125-145

Satterwhite MA (1975) Strategy-proofness and arrow's conditions: existence and correspondence theorems for voting procedures and social welfare functions. J Econ Theory 10:187-217

Schmeidler D (1969) The nucleolus of a characteristic function game. SIAM J Appl Math 17:1163-1170

Shapley LS (1971) Cores of convex games. Int J Game Theory 1:11-26

Shapley LS (1953b) A value for n-person games. In: Kuhn HW, Tucker AW (eds) Contributions to the theory of games II (Annals of mathematics studies 28). Princeton University Press, Princeton, pp 307-317

Shapley LS, Shubik M (1996) Quasi-cores in a monetary economy with nonconvex preferences. Econometrica 34(4):805-827

Shapley L (1953a) Additive and non-additive set functions. Ph.D. thesis. Department of Mathematics, Princeton University

Tax Foundation (2007) Federal taxes paid vs. federal spending received by state, 1981-2005. http:// taxfoundation.org/article/federal-taxes-paid-vs-federal-spending-received-state-1981-2005

Thomson W (2003) Axiomatic and game-theoretic analysis of bankruptcy and taxation problems: a survey. Math Soc Sci 45:249-297

Thomson W (2019) How to divide when there isn't enough. Econometric society monographs. Cambridge University Press, Cambridge

Tijs S, Driessen TSH (1986) Extensions of solution concepts by means of multiplicative-tax games. Math Soc Sci 12(1):9-20

Tijs S (1981) Bounds for the core and the $\tau$-value. In: Moeschlin O, Pallaschke D (eds) Game theory and mathematical economics. North Holland, Amsterdam, pp 123-132

Uriel E, Barberán R (2007) Las balanzas fiscales de las comunidades autónomas con la Administración Pública Central (1991-2005). Fundación BBVA, Bilbao (in Spanish)

van den Brink R (2001) An axiomatization of the Shapley value using a fairness property. Int J Game Theory 30:309-319

Van den Noweland A, Borm P, van Goldstein BW, Groot Bruinderink R, Tijs S (1996) A game theoretic approach to problems in telecommunication. Manag Sci 42(2):294-303

Wildasin DE (1988) Nash equilibria in models of fiscal competition. J Public Econ 35:229-240 
Young P (1988) Distributive justice in taxation. J Econ Theory 44:321-335

Young P (1990) Progressive taxation and equal sacrifice. Am Econ Rev 80(1):253-266

Zabalza A, López-Laborda J (2014) The uneasy coexistence of the Spanish Foral and common regional finance systems. IVIE, WP-EC 2014-02

Publisher's Note Springer Nature remains neutral with regard to jurisdictional claims in published maps and institutional affiliations. 